\title{
Analyzing and Forecasting Rocky Mountain Lee Cyclogenesis Often Associated with Strong Winds
}

\author{
David M. Schultz And Charles A. Doswell III \\ NOAA/National Severe Storms Laboratory, Norman, Oklahoma
}

(Manuscript received 3 May 1999, in final form 22 November 1999)

\begin{abstract}
Since numerical forecast models often err in predicting the timing and location of lee cyclogenesis, a physically based method to diagnose such errors is sought. A case of Rocky Mountain lee cyclogenesis associated with strong winds is examined to explore the transformation from a stationary lee trough to a mobile midlatitude cyclone (hereafter, departure). Up to $12 \mathrm{~h}$ before departure, a pronounced surface pressure trough travels eastward across western North America at an average speed of $22 \mathrm{~m} \mathrm{~s}^{-1}$. Several methods are employed to examine the structure and evolution of the pressure field: total sea level pressure, time series at individual stations, isallobars, and bandpass filtering. Bandpass filtering of the observed sea level pressure data is useful for clarifying the movement of the mobile trough through the complex terrain. Quasigeostrophic height-tendency diagnostics show that the mobile pressure trough is related to the traveling mid- to upper-tropospheric vorticity maximum that is responsible for departure. At many stations, surface temperature changes associated with this pressure trough are not consistent with those commonly associated with surface frontal passages. To test the hypothesis that mobile pressure troughs are associated with departure, a five-winter climatology of 111 southern Alberta lee cyclones is constructed. Sixty-two percent of these events feature an upstream pressure minimum 3-9 h prior to departure, in a manner resembling the case study. Seventy-six percent of these 111 events are associated with reports listed in Storm Data, indicating the potential severity of these storms.
\end{abstract}

\section{Introduction}

A common winter weather hazard for the northern lee slopes of the Rocky Mountains is strong wind. When this wind is relatively warm and has a westerly, or downslope, component, it is known as a chinook (e.g., Huschke 1959; Nkemdirim 1996). One type of chinook, the so-called frontal chinook (Oard 1993), occurs after a stationary lee trough develops into a mobile midlatitude cyclone and moves away from the lee slopes of the Rocky Mountains. This entire process is generically referred to as lee cyclogenesis (e.g., Pierrehumbert 1986), but we will refer to the movement of the lee trough or closed low away from the lee slopes of the mountains as departure. In the United States, these strong winds tend to be located in the Livingston Box (Waters 1970), a region just to the lee of the Montana and Wyoming Rockies centered near Livingston, Montana, favored for strong wind events. The strong winds occurring in the wake of departure are believed to be caused by a combination of air accelerating down a strong isallobaric gradient and the downward advection of higher-mo-

Corresponding author address: Dr. David M. Schultz, NOAA/National Severe Storms Laboratory, 1313 Halley Circle, Norman, OK 73069

E-mail: schultz@nssl.noaa.gov mentum air (e.g., Waters 1970, p. 27; Oard 1993; Kapela et al. 1995). Along the immediate lee slopes, mountainwave amplification may also be contributing to strong downslope winds (e.g., Durran 1986). Additional hazards can accompany lee cyclogenesis (e.g., heavy snow, heavy rain, and flooding), as noted for the northern United States (this article, section 5; Lackmann and Gyakum 1999) and the Canadian prairies (Stewart et al. 1995, section 3).

The slopes of southern Alberta are a favored location for lee cyclogenesis (e.g., Bowie and Weightman 1914; Petterssen 1956; Chung et al. 1976; Zishka and Smith 1980; Whittaker and Horn 1984; Nielsen and Dole 1992) and many previous studies have explored synoptic-scale aspects of Rocky Mountain lee cyclogenesis using observational (e.g., Newton 1956; McClain 1960; Carlson 1961; Hovanec and Horn 1975; Locatelli et al. 1989) and modeling (e.g., Bates 1990; Bannon 1992; Steenburgh and Mass 1994; Davis 1997) approaches. In particular, Palmén and Newton (1969, pp. 344-349) and Steenburgh and Mass (1994, Fig. 22) present similar conceptual models illustrating the typical development of an Alberta low (e.g., Bowie and Weightman 1914; Huschke 1959), colloquially known as an Alberta clipper. This development occurs as follows.

Initially, a cyclone over the eastern North Pacific Ocean approaches the west coast of North America. As 
the tropospheric flow crossing the Rocky Mountains increases, lee troughing occurs, fixed to the lee slopes of the mountains by warming due to dry-adiabatic descent. Eventually, a mid- to upper-tropospheric absolute vorticity maximum (i.e., short-wave trough or jet streak) may couple with the lee trough, causing the lee trough to become mobile (departure). A review of previous literature on lee troughing and lee cyclogenesis can be found in Steenburgh and Mass (1994, section 2).

Idealized-modeling studies (e.g., Buzzi et al. 1987; Bannon 1992; Davis 1997) provide insight into these observations. As the primary cyclone encounters the topography, it weakens and decelerates, curving northward. Redevelopment occurs on the lee side, south of the region of incidence of the dissipating primary cyclone. The cyclolysis of the primary cyclone and cyclogenesis of the lee trough are viewed as manifestations of the interaction of the mountain with the baroclinic wave associated with the primary and lee cyclones. The strength and location of the surface cyclones are modulated by the wave-mountain interaction.

Thus, forecasting the timing of departure of the lee cyclone would appear to be conceptually simple: given knowledge of the movement of the upper-level vorticity maximum, the timing of the departure could be easily determined. In practice, forecasting lee cyclogenesis is more difficult.

Numerous studies have shown that numerical forecast models historically have handled lee cyclogenesis poorly. For example, the Nested Grid Model (NGM) has a well-documented bias to forecast cyclones that are too intense over land, in particular, in the lee of the Rockies (e.g., Grumm and Siebers 1989, 1990; Alexander and Young 1990; Kousky and Grumm 1993b). Rocky Mountain lee cyclones in the United States tend to be forecast too far north and east (e.g., Mullen and Smith 1993; Smith and Mullen 1993), whereas Rocky Mountain lee cyclones in Canada tend to be forecast too far north and west (e.g., Mullen and Smith 1993; Smith and Mullen 1993; Hutchinson 1995). This northward bias may be related to the NGM's inability to capture fully the wavemountain interaction described earlier. Also, the position errors tend to be aligned along the direction of travel of the cyclones, indicating that the NGM has difficulty diagnosing the cyclone speed, the timing of cyclone formation, and/or the timing of departure (e.g., Mullen and Smith 1990; Grumm et al. 1992; Hutchinson 1995). Brown and Szoke (1994) have found that these surfacecyclone movement errors are related to similar movement errors with the associated upper-level vorticity maxima. Thus, the ability of the models to forecast departure accurately depends upon their ability to forecast the movement of the upper-level features accurately.

Unfortunately, other National Centers for Environmental Prediction (NCEP) operational forecast models have produced similar errors in the lee of the Rockies, errors that have been documented as early as the sixlayer primitive-equation model (Leary 1971), the seven- layer primitive-equation model (Colucci and Bosart 1979), and the Limited-Area, Fine-Mesh Model (LFM; Colucci and Bosart 1979; Junker et al. 1989), and in more recently developed modeling systems: the aviation run of the Global Spectral Model (AVN; e.g., Grumm and Siebers 1990; Smith and Mullen 1993; Grumm 1993), the Medium-Range Forecast Model (MRF; e.g., Walker and Davis 1995), and the 80-km version of the Eta Model (e.g., Kousky and Grumm 1993a,b; Brown and Szoke 1994; Mesinger et al. 1996).

Similar quantitative studies have not been performed for the current suite of higher-resolution models. Anecdotal evidence, however, indicates that the Rapid Update Cycle (RUC; e.g., J. Brown 1999, personal communication) appears to have similar biases, whereas the $32-\mathrm{km}$ version of the Eta Model sometimes produces lee cyclones too far south and not deep enough (see http://www.comet.ucar.edu/nwplessons/etalesson $2 /$ biasesbackground.htm).

Such model biases have been attributed to inadequate upstream data for initialization, coarse model resolution and terrain representation, various sea level pressure reduction techniques, and different representations of form drag. While numerical forecast models have improved and continue to improve, a need always will exist to evaluate when forecasts deviate from the observations, particularly in regions of complex terrain where analysis is more challenging. This paper offers such a method.

Given the potential difficulty of employing numerical models to forecast lee cyclogenesis and cyclone departure, knowing the location of upper-level vorticity maxima from the observations in near-real time becomes of primary importance. The wind and thermal structures associated with upper-level vorticity maxima, however, can be observed most reliably using upper-air sounding data, which are only available every $12 \mathrm{~h}$ operationally. Dark regions in satellite-based water vapor imagery [representing dry upper-tropospheric regions typically formed by subsidence behind upper-level vorticity maxima; e.g., Demirtas and Thorpe (1999)] can be apparent in some cases, when not obscured by mountain-waveinduced clouds. Unfortunately, vorticity maxima may be difficult to detect as they move into the climatological ridge often present over western North America (e.g., Sanders 1988, Fig. 7; Bluestein 1993, Fig. 1.72a; Lackmann et al. 1996, Fig. 1). Additional tools to locate vorticity maxima indirectly between synoptic times (0000 and 1200 UTC) would be of some value to forecasters. The importance of knowing the location of upper-level vorticity maxima cannot be understated, since the precursor lee trough can be manifest for up to several days before departure, often with little indication that departure may be imminent. Thus, we believe that forecasts of the timing of departure can be improved by tracking upper-level features.

Therefore, the purpose of this paper is to examine a case of southern Alberta lee cyclogenesis and to develop 


\section{STORM DATA REPORTS: $13-14$ DECEMBER 1988}

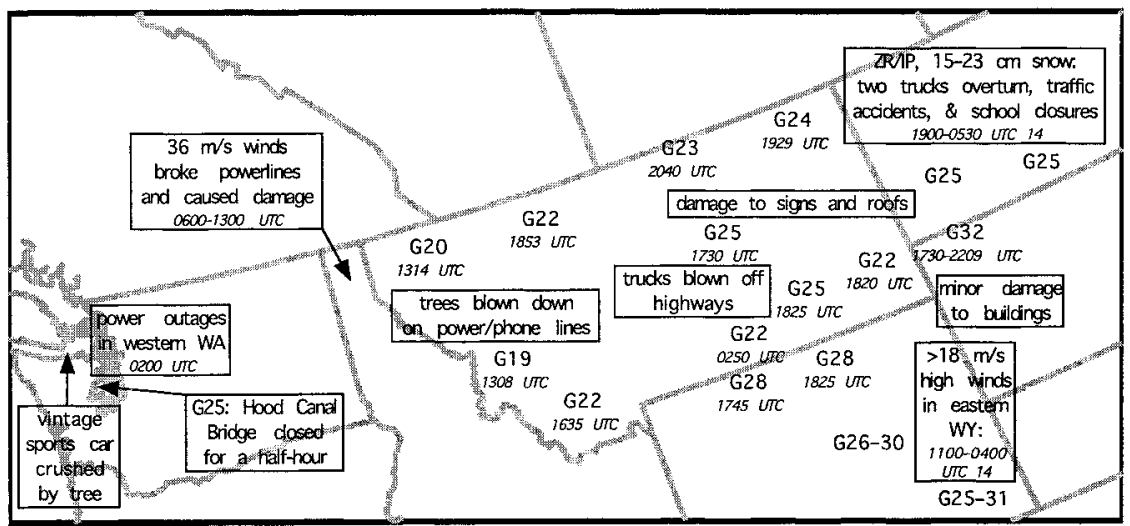

FIG. 1. Reports from NOAA (1988) for 13-14 Dec 1988 for WA, ID, MT, WY, ND, and SD. All reports are from 13 Dec, unless specified by "14" following the time of the report. "Gnn" represents the location of a wind gust report of $n n \mathrm{~m} \mathrm{~s}^{-1} . \mathrm{ZR}=$ freezing rain; IP = ice pellets (sleet).

observational tools to aid forecasters in predicting when departure will occur. In section 2, an observational analysis of a lee cyclone that was associated with strong winds over much of the northwestern United States is presented, leading to a potential method for improving short-term forecasting of departure. A mesoscale model simulation of this case is described in section 3 and is used to diagnose the lee cyclogenesis in section 4 . This case study analysis motivates the construction and interpretation of a larger dataset of lee cyclogenesis events in section 5. Finally, section 6 presents a concluding discussion.

\section{Case study: Analysis of observations}

The lee cyclogenesis event of 12-14 December 1988 was associated with numerous Storm Data (NOAA 1988) reports of $20-35 \mathrm{~m} \mathrm{~s}^{-1}$ wind gusts (Fig. 1). The majority of these reports in Montana, Wyoming, and the Dakotas were associated with strong westerly chinook winds, which occurred between 1600 and 2200 UTC 13 December after the lee cyclone moved away from the mountains. As the surface cyclone moved into the Dakotas, freezing rain, sleet, and snow fell, causing numerous traffic accidents and school closures (Fig. 1). Our analysis below focuses on departure, $1-16 \mathrm{~h}$ before the majority of these leeside wind events occur.

\section{a. Evolution}

At 1200 UTC 12 December 1988 (12/12: times hereafter abbreviated as "day/hour UTC"), a cyclone along $140^{\circ} \mathrm{W}$ approached the west coast of North America (Fig. 2a). Satellite imagery of this storm from 0016 to 2316 UTC 12 December 1988 can be found in Schultz and Doswell (1999, Fig. 4). By 13/00, the cyclone $(\sim 1000 \mathrm{hPa})$ had reached the coast of North America, just east of the Queen Charlotte Islands (Fig. 2b). Pressure falls at this time, however, were already occurring farther inland (Fig. 3a).

At 13/06, multiple low centers and troughs were apparent, as the cyclone reorganized amid the complex terrain of western North America (Fig. 2c). The remains of the landfalling primary cyclone were located in western British Columbia. A second relative minimum in sea level pressure (as well as altimeter setting; not shown) was apparent over the Fraser River Valley in central British Columbia, a feature also analyzed by Steenburgh and Mass (1996, Figs. 4d and 7e,f) for a similar landfalling Pacific cyclone. Although the sparse observations outside the valley prevent a definitive conclusion regarding the nature of this troughing, hourly surface analyses (not shown) suggest that this trough formed in situ, rather than being a mobile feature associated with the landfalling cyclone. Whether this pressure minimum is genuine or a by-product of sea level pressure reduction at high-elevation stations cannot be conclusively determined from this analysis, but, as suggested in section 2b, this Fraser River Valley trough appears to be genuine. A third minimum in sea level pressure was a trough in the lee of the Rocky Mountains (Fig. 2c), associated with sea level pressure falls exceeding $3 \mathrm{hPa} \mathrm{h}^{-1}$ (Fig. 3b).

By 13/09 (Fig. 2d), pressure rose in the Fraser River Valley and the Rocky Mountain lee trough developed further, with the 996-hPa minimum pressure immediately adjacent to the steep terrain. Two hours later (13/ 11; Fig. 2e), the central pressure deepened $2 \mathrm{hPa}$ and the trough extended farther southeastward along the lee slopes of Montana and Wyoming. The largest pressure falls (exceeding $2 \mathrm{hPa} \mathrm{h}^{-1}$ ), however, occurred in southeast Alberta and northern Montana (Fig. 3c). Within the next hour (13/12; Fig. 2f), the low center jumped 300 $\mathrm{km}$ to southeast Alberta, as pressures rose rapidly (3 

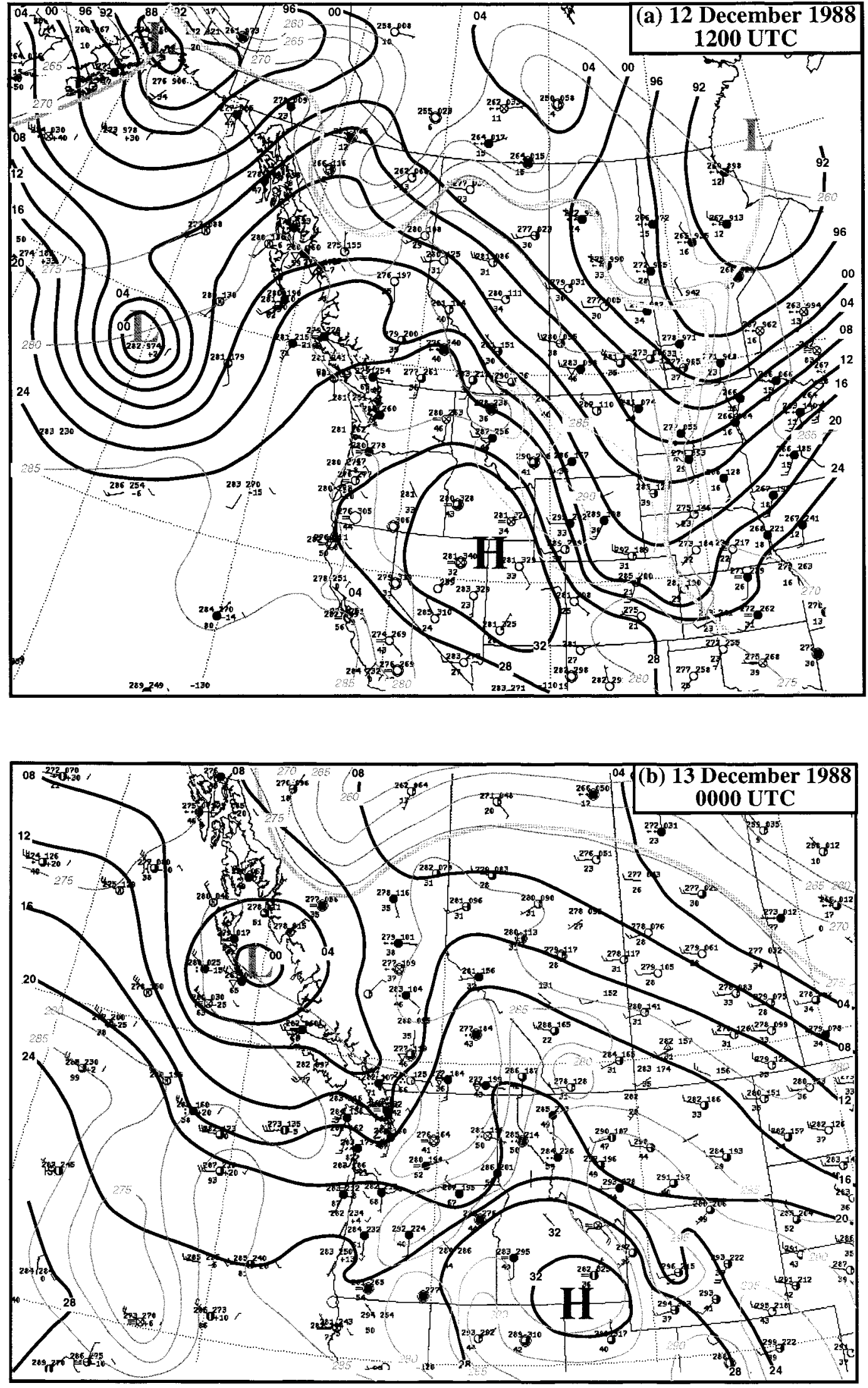

FIG. 2. Surface maps: sea level pressure (thick solid lines every $4 \mathrm{hPa}$; light gray lines every $2 \mathrm{hPa}$ where needed for clarity); surface potential temperature (thin solid lines every $5 \mathrm{~K}$ ), and surface frontal boundaries (dark gray lines). 

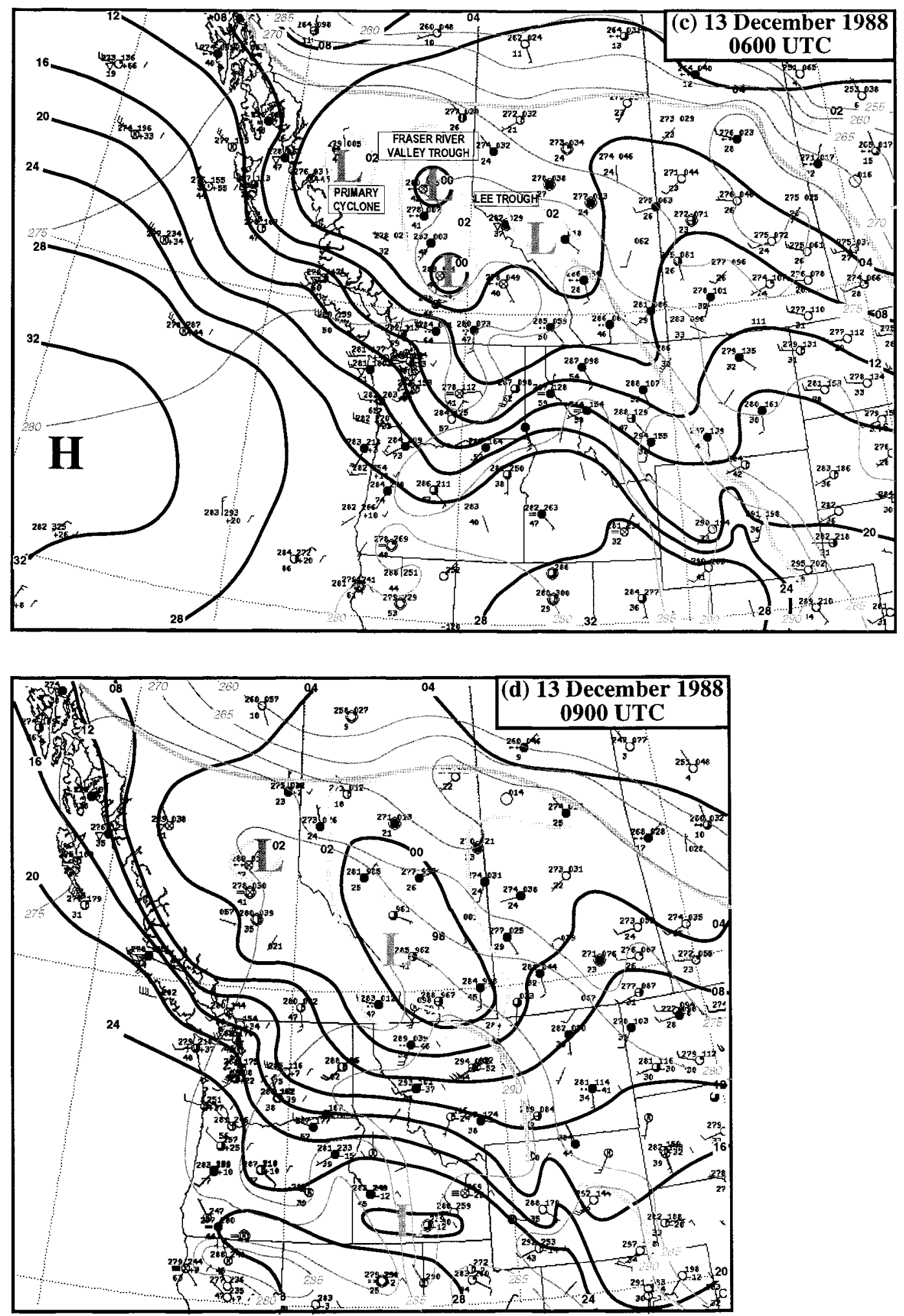

FIG. 2. (Continued) All available data were not plotted for clarity. Surface station models are standard, except as noted: surface potential temperature $(\mathrm{K})$ is in the upper-left corner of the station model, surface mixing ratio $\left(\mathrm{g} \mathrm{kg}^{-1}\right.$ $\times 10$ ) is in the lower-left corner of the station model, and surface winds are in $\mathrm{m} \mathrm{s}^{-1}$ (one pennant, full barb, and half 

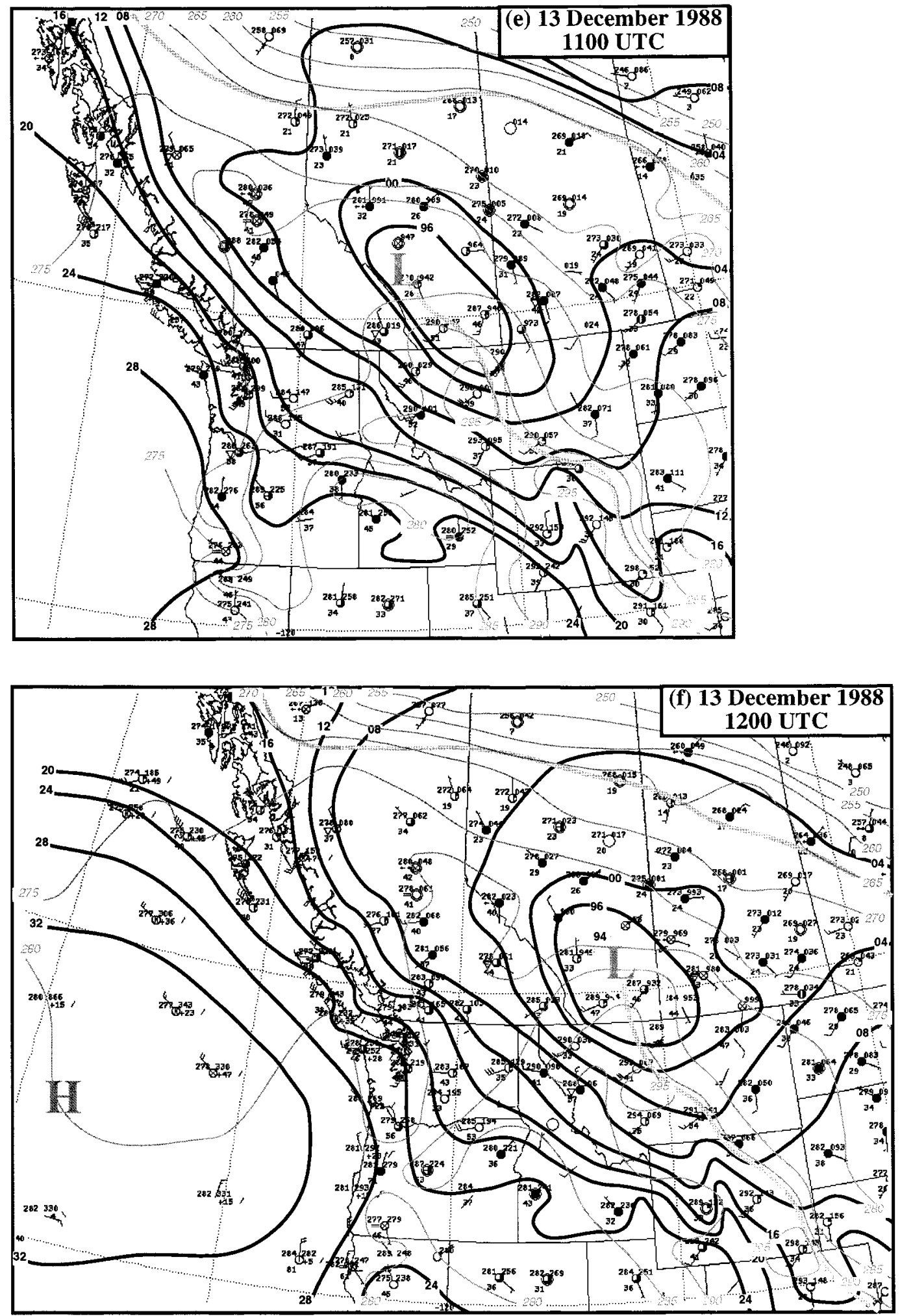

FIG. 2. (Continued) barb denote 25,5 , and $2.5 \mathrm{~m} \mathrm{~s}^{-1}$, respectively); large L's and H's indicate position of surface cyclone and anticyclone centers. Low centers/troughs are labeled in (c): (a) 1200 UTC 12 Dec, (b) 0000 UTC 13 Dec, (c) 0600 UTC 13 Dec, (d) 0900 UTC 13 Dec, (e) 1100 UTC 13 Dec, and (f) 1200 UTC 13 Dec. 

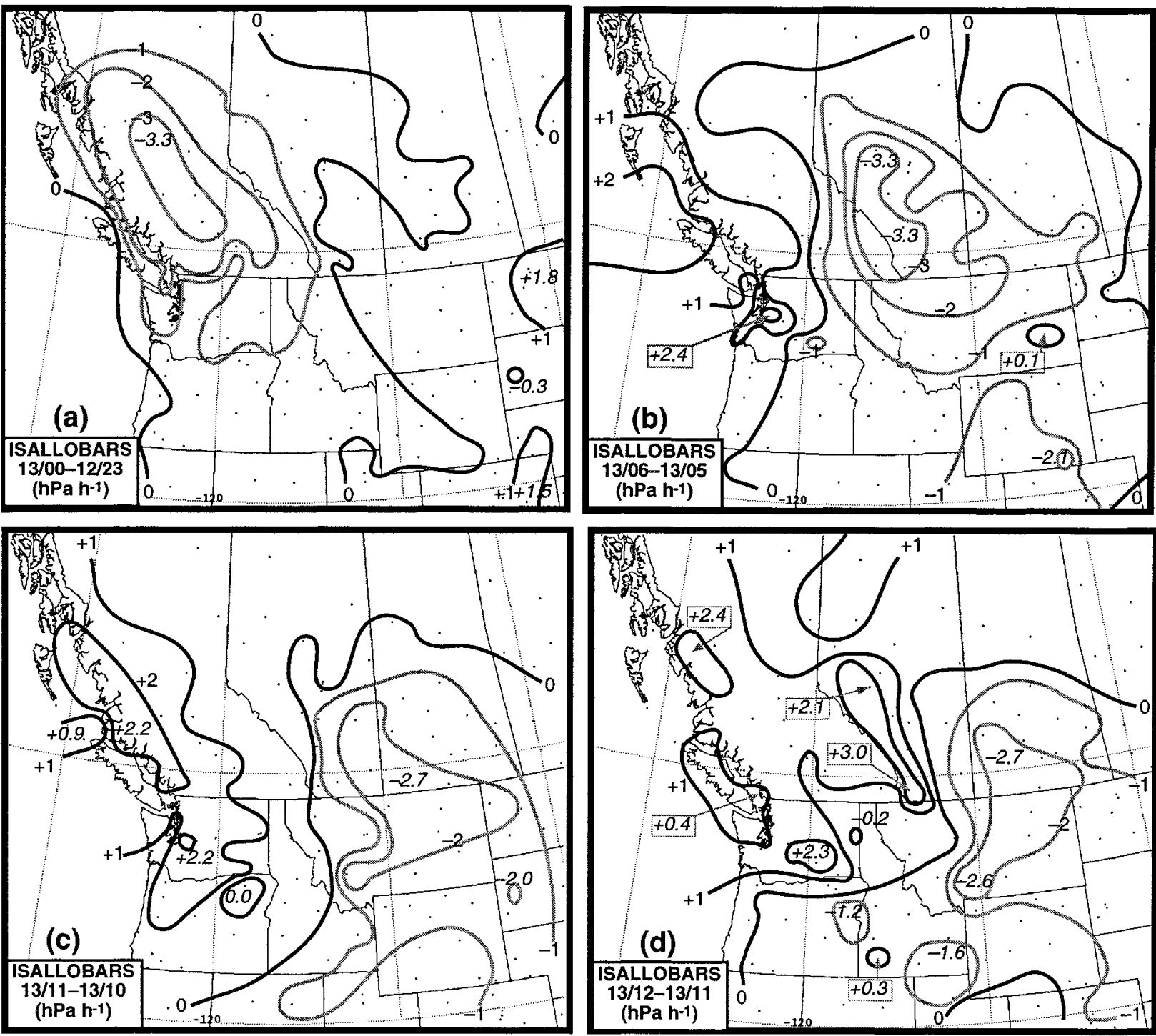

FIG. 3. One-hour observed sea level pressure changes (every $1 \mathrm{hPa} \mathrm{h}^{-1}$ ): gray (black) lines represent negative (positive and zero) isallobars or pressure falls (rises). Numbers in italics represent local maxima and minima. Dots represent typical locations of available stations. (a) Pressure change between 2300 UTC 12 Dec and 0000 UTC 13 Dec 1988, (b) pressure change between 0500 UTC 13 Dec and 0600 UTC 13 Dec 1988, (c) pressure change between 1000 UTC 13 Dec and 1100 UTC 13 Dec 1988, and (d) pressure change between 1100 UTC 13 Dec and 1200 UTC 13 Dec 1988.

hPa h${ }^{-1}$; Fig. 3d) immediately along the lee slopes. Maximum pressure falls exceeding $2 \mathrm{hPa} \mathrm{h}^{-1}$ continued to be located east of the low center (Fig. 3d). Thus, the movement of the lee cyclone away from the mountains was very abrupt, despite the comparative longevity of the lee trough. In this case, the trough existed for $11 \mathrm{~h}$ (0100-1100 UTC) before rapidly moving away from the terrain, movement which commenced within $1 \mathrm{~h}$.

\section{b. The value of pressure analyses in this case}

Although tracking pressure features through the complex terrain of western North America is difficult in real time owing to pressure-reduction problems (e.g., Pauley
1998 and references within) and the sparsity of observations, surface analyses in this case (Fig. 2) indicated that no single pressure center traversed the Canadian Rockies. Instead, the discontinuous evolution appeared to consist of a dying, landfalling Pacific cyclone and rebirth from the lee trough, as in conceptual models of Rocky Mountain lee cyclogenesis (Palmén and Newton 1969, pp. 344-349; Steenburgh and Mass 1994, Fig. 22). Since our ability to anticipate lee cyclogenesis would be enhanced by tracking a single feature through the mountains, these sea level pressure analyses were of limited utility for forecasting lee cyclogenesis in this case.

Another method that has been proposed to follow 
mobile features is the isallobaric field. As shown in Fig. 3 , the observed isallobars were useful in examining the magnitude and location of sea level pressure changes, yet pressures were falling for $6-12 \mathrm{~h}$ in southeastern Alberta before departure (Figs. 3b-d and 4a). In this case, detecting departure from the isallobaric field was masked by the overall pressure falls along the lee slopes. The arrival of the zero isallobar into Alberta at 13/11 (Fig. 3c), however, was coincident with departure. This relationship is substantiated by time series of altimeter setting (hereafter, also referred to as pressure) from western North American stations, indicating that a single trough or pressure minimum (zero isallobar) progressed across western North America (Fig. 4a), despite the complicated evolution analyzed on the surface maps (Fig. 2). Constructing a map of the isochrones of this pressure minimum confirms that 1100 UTC represents the time of minimum pressure along the lee slopes immediately prior to departure (Fig. 4b). As meteorologists, we are drawn to the maxima and minima of a field of isopleths. We argue, however, that tracking the location of the zero isallobar may be a better indicator to the timing of departure than tracking isallobaric minima.

These pressure changes during the case study of lee cyclogenesis presented here occur during a time of relatively small pressure changes [less than $0.5 \mathrm{mb}(3 \mathrm{~h})^{-1}$ ] due to diurnal effects (Mass et al. 1991, Fig. A1). Therefore, the pressure-fall features seen in Figs. 2-4 are primarily due to synoptic-scale processes, not diurnal effects. The nature of the mobile pressure trough will be explored further in section $4 \mathrm{~b}$.

As further demonstration of the structure and evolution of the sea level pressure fields, we construct pressure-anomaly maps using a bandpass filter in both space and time using the methodology described in Doswell (1977) of differencing two low-pass filters. The response functions of the space and time filters (Figs. 5a,b) are designed to highlight subsynoptic-scale features (300-1500 km and 3-20 h), while eliminating smallscale noise and synoptic-scale patterns. As a result, this bandpass filter is well suited to the analysis of the mobile pressure features in this case. The bandpass-filtered pressure analyses also minimize sea level pressure reduction errors, although both the bogus semidiurnal cycle caused by the temperature-averaging scheme used in sea level pressure reduction (Mass et al. 1991) and the genuine atmospheric semidiurnal cycle would still be present in the bandpass-filtered fields.

At $13 / 00$, the bandpass-filtered pressure minimum was making landfall north of Vancouver Island (Fig. 6a), ${ }^{1}$ in agreement with the observed map at this time (Fig. 2b). By 13/03, the bandpass-filtered pressure was decreasing over central British Columbia with a second

\footnotetext{
${ }^{1}$ Animation of the 13-h sequence of bandpass-filtered sea level pressure from $13 / 00$ to $13 / 12$ can be found at http://www.nssl. noaa.gov/ schultz/schultzanddoswell.shtml.
}

minimum along the coast (Fig. 6b), giving support for the Fraser River Valley minimum being a separate feature from the landfalling cyclone (see also Fig. 2c). The minimum over central British Columbia (Fig. 6c) remained in place for $3 \mathrm{~h}$ before moving abruptly toward the lee slopes of the Rockies (Fig. 6d), reminiscent of the southeastward jump in idealized models of lee cyclogenesis (section 1). After 13/09, the bandpass-filtered minima slowly drifted southeastward along the lee slopes into Montana (Figs. 6e,f), consistent with the southeastward extension of the lee trough after 0900 UTC (cf. Figs. 2d,e). Thus, the bandpass-filtered pressure fields illustrate their utility in highlighting the mobile pressure features responsible for departure.

\section{c. The lack of value of frontal analyses in this case}

We define a front as a strong potential temperature discontinuity and cyclonic wind shift, consistent with the definition applied in Sanders and Doswell (1995) and Sanders (1999a). We explore the relationship between observed weather at different stations and the passage of the mobile pressure minimum through time series of surface weather from six stations (Fig. 7). Quillayute, Washington (UIL; see Fig. 4a for station locations), on the Pacific coast reached a minimum in pressure at 13/02, as the wind shifted from southerly to westerly (Fig. 7a). The pressure minimum was coincident with the onset of a gentle $2^{\circ}-3^{\circ} \mathrm{C}$ temperature decrease and a $10^{\circ} \mathrm{C}$ dewpoint temperature decrease over a period of $12-18 \mathrm{~h}$. As the pressure minimum moved inland, it passed over Penticton (YYF) in the northsouth-oriented Okanagan River Valley in south-central British Columbia. After the pressure minimum passed Penticton at $13 / 06$, the wind shifted direction very little and the temperature and dewpoint increased until 13/ 11 (Fig. 7b). Thus, surface warming, not cooling, accompanied the trough passage at Penticton. The pressure minimum at Spokane, Washington (GEG), occurred at $13 / 06$, accompanied by a gradual wind shift from southsouthwesterly to southwesterly (Fig. 7c). Temperatures decreased about $5^{\circ} \mathrm{C}$ within $6 \mathrm{~h}$ after the trough passage. In the lee of the Rockies, Lethbridge, Alberta (YQL), is known for being particularly susceptible to strong chinook winds (e.g., Osmond 1941; Longley 1967; Nkemdirim 1996). At 13/10, the winds shifted from south to west (Fig. 7d), signaling the onset of downslope winds and imminent departure of the lee cyclone. By $13 / 17$, the wind reached a peak magnitude of $16.5 \mathrm{~m}$ $\mathrm{s}^{-1}$, before veering northwesterly and decreasing in magnitude. Despite the strong downslope winds, temperatures at Lethbridge remained relatively steady from $13 / 13$ until the wind shift to northwesterly at $13 / 18$. This observation may indicate that any downslope warming was offset by cold advection. In the Montana Rockies, Kalispell (FCA) reached its minimum pressure at 13/ 11 , followed by a wind shift from southerly to southwesterly and an abrupt $4^{\circ} \mathrm{C}$ temperature decrease in 2 


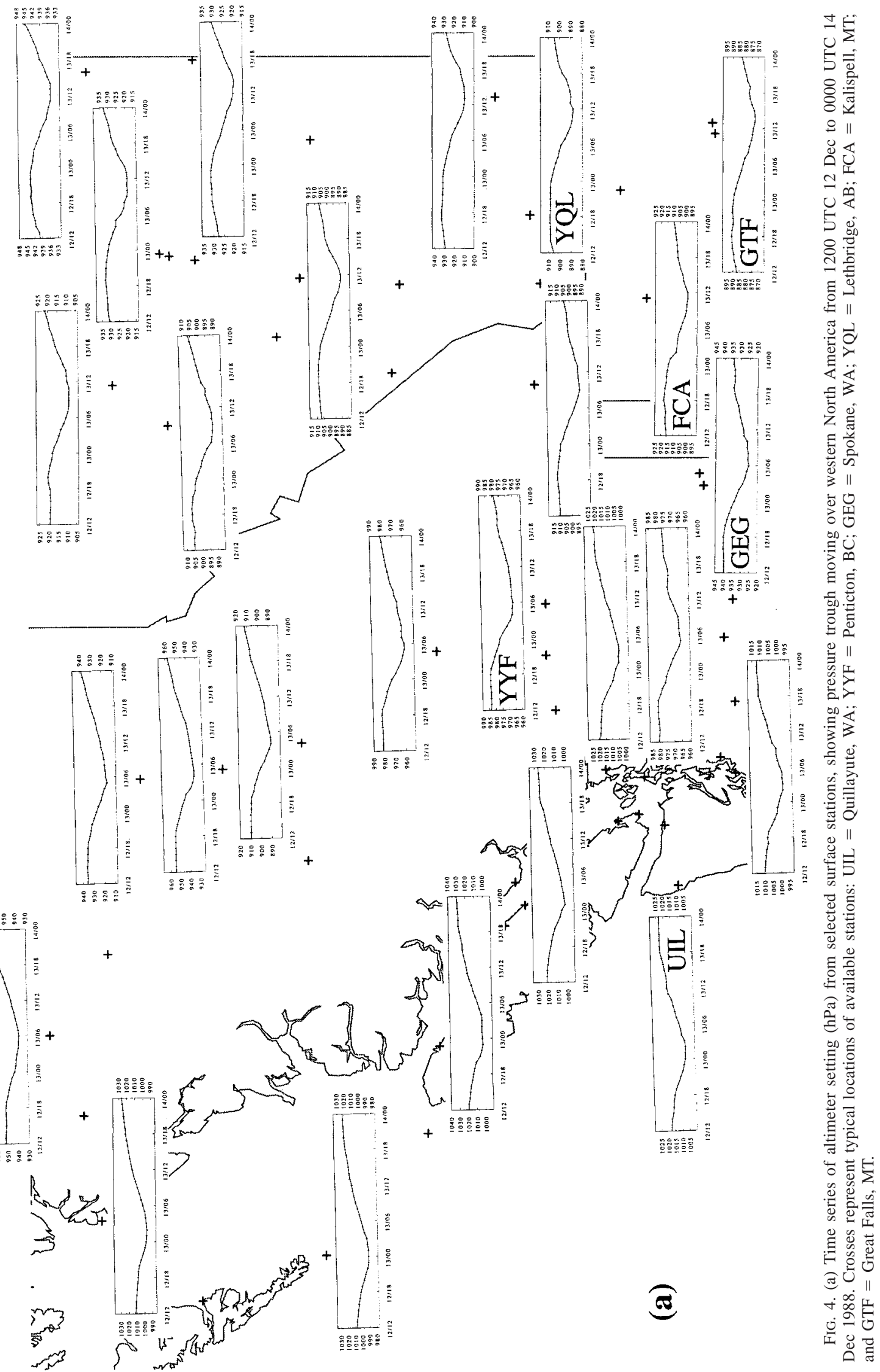




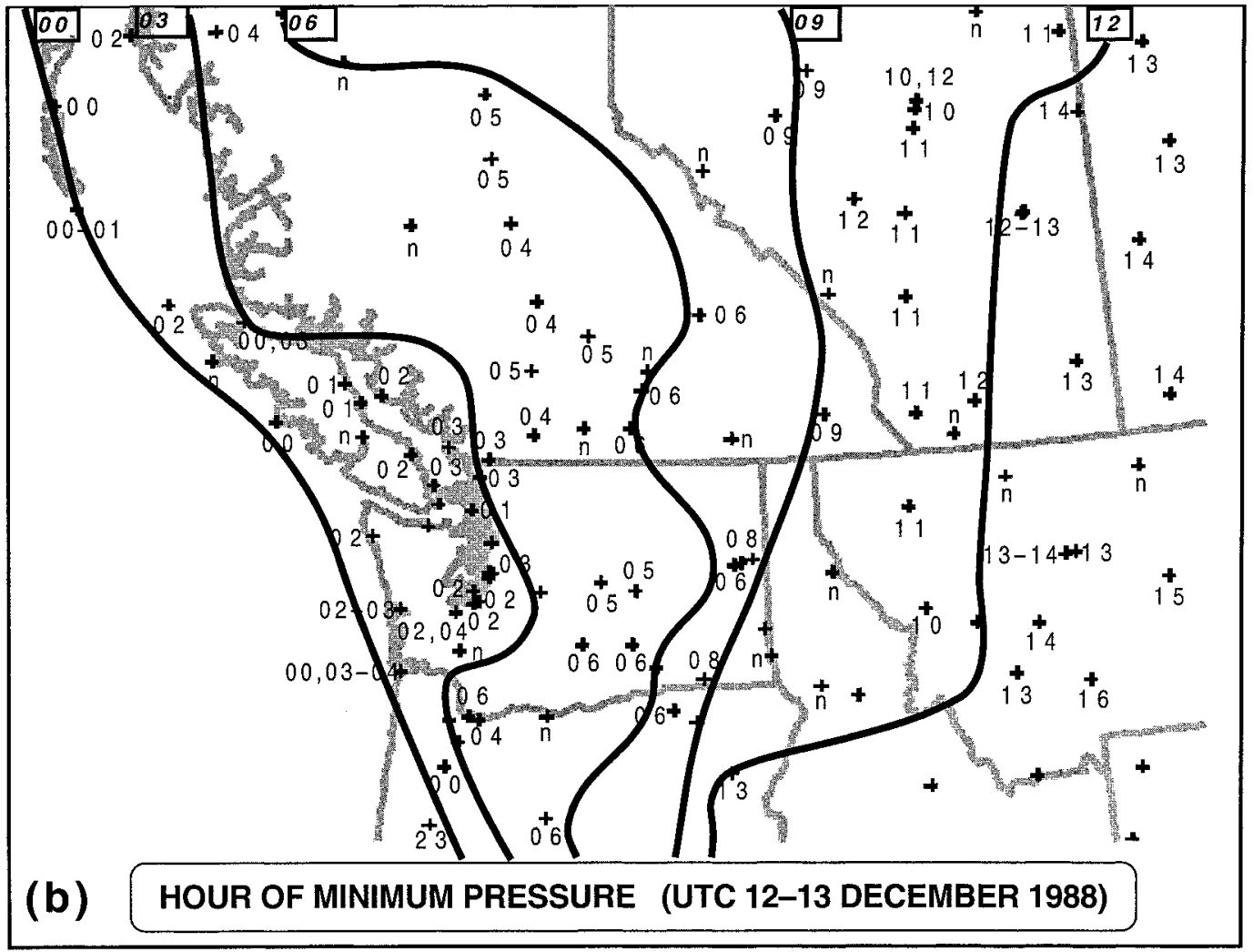

FIG. 4. (Continued) (b) Isochrones (hour UTC on $13 \mathrm{Dec}$ 1988) of pressure trough moving over western North America. Crosses represent typical locations of available stations; numbers represent hour UTC on 13 Dec 1988 (except 23, which represents 2300 UTC 12 Dec) of time of minimum altimeter setting; "n" represents inadequate data at station to determine time of pressure minimum to within 1 -h precision.

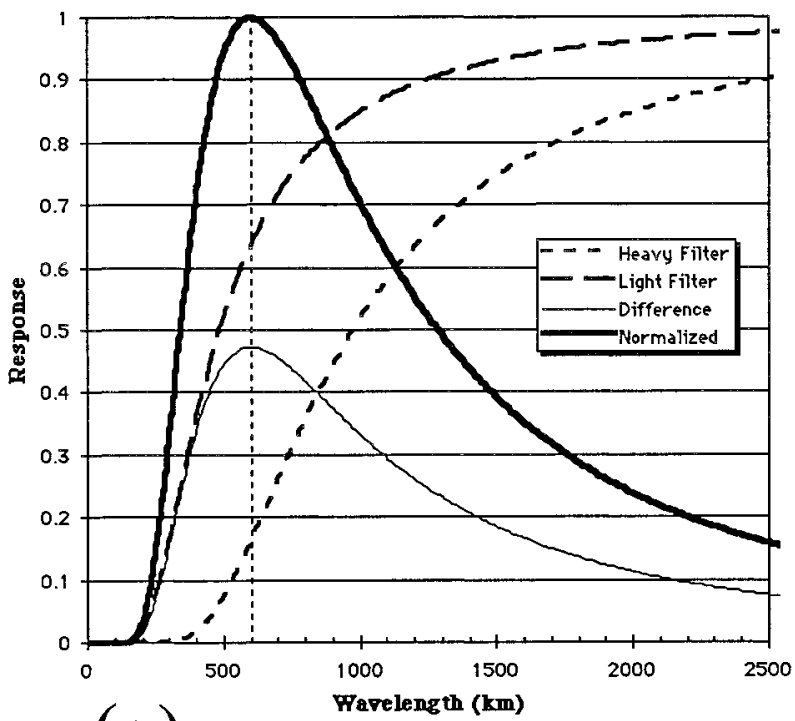

(a)

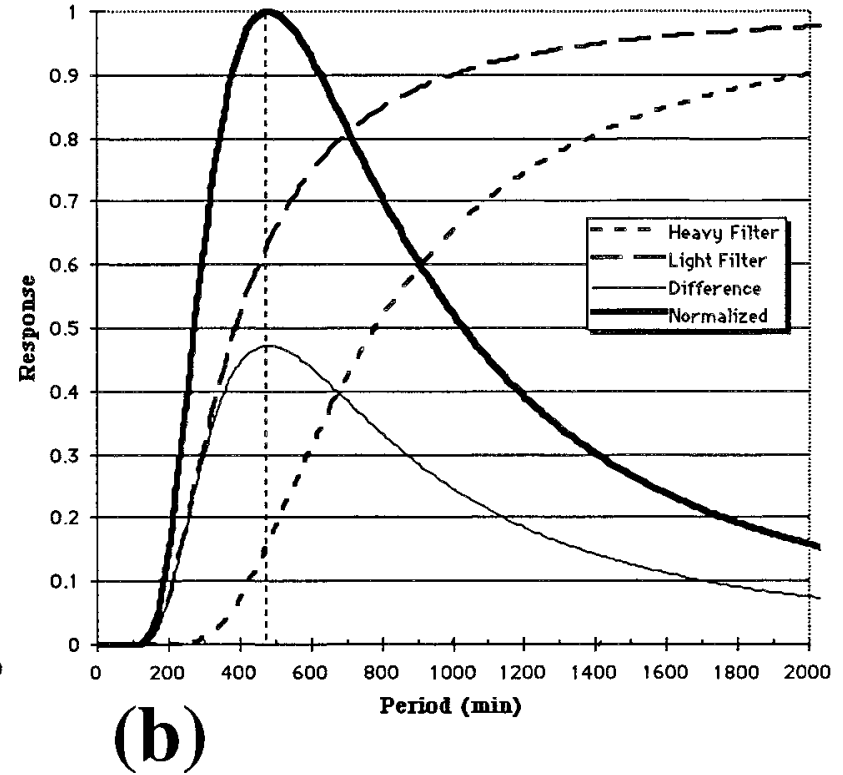

(b)

FIG. 5. (a) Response functions for low-pass and bandpass spatial filters. (b) Response functions for low-pass and bandpass temporal filters. 

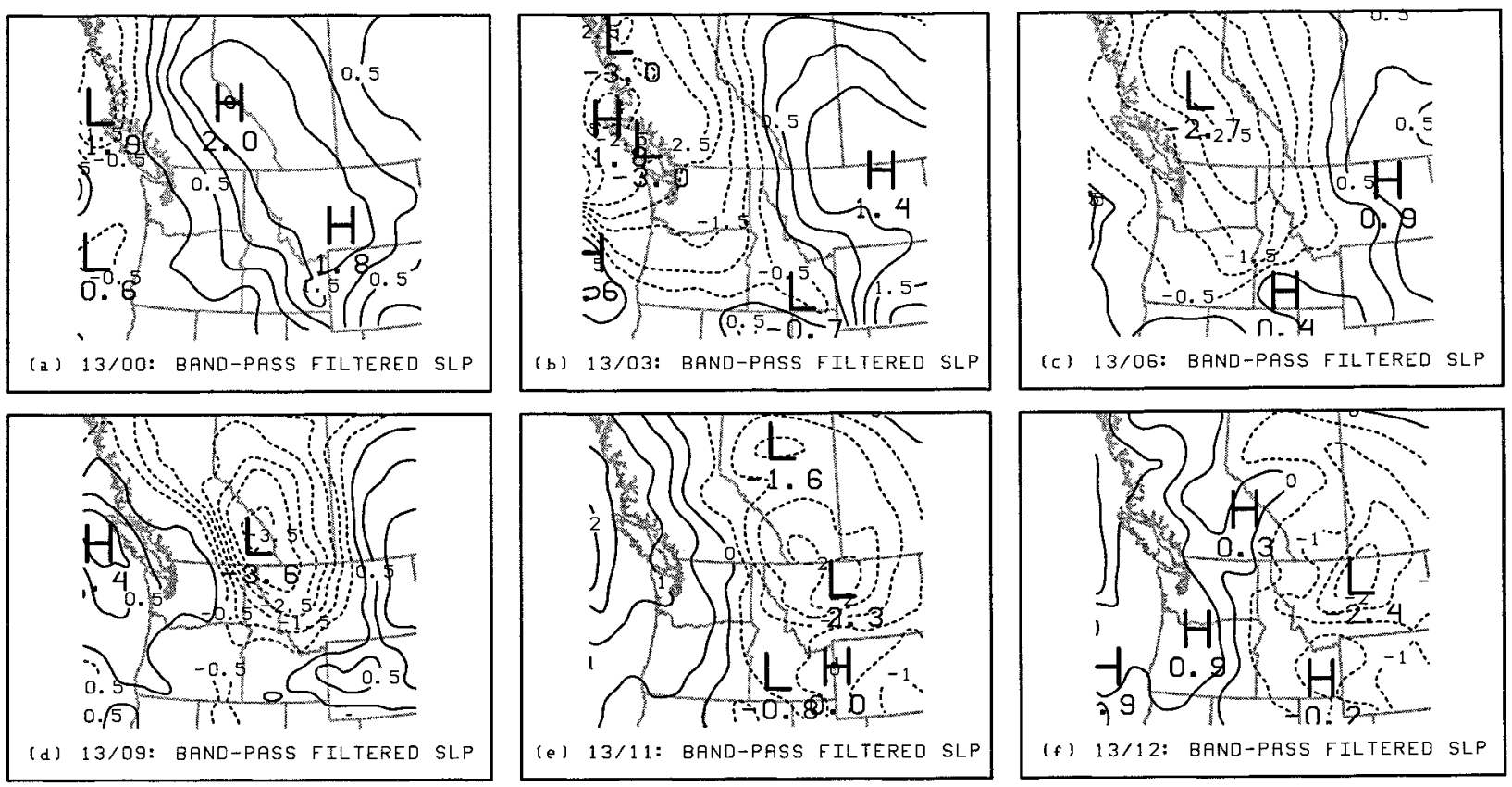

FIG. 6. Bandpass-filtered observed sea level pressure (every $0.5 \mathrm{hPa} \mathrm{h}^{-1}$ ): dashed (solid) lines represent negative (positive and zero) bandpass-filtered pressure falls (rises): (a) 0000 UTC 13 Dec, (b) 0300 UTC 13 Dec, (c) 0600 UTC 13 Dec, (d) 0900 UTC 13 Dec, (e) 1100 UTC 13 Dec, and (f) 1200 UTC 13 Dec 1988.

h (Fig. 7e). Downwind of the lee slopes, a shift from weak southerlies to $15 \mathrm{~m} \mathrm{~s}^{-1}$ westerlies (13/08) at Great Falls, Montana (GTF) preceded the pressure minimum at 13/13-13/14, followed by a shift to $15-20 \mathrm{~m} \mathrm{~s}^{-1}$ westerlies (Fig. 7f). Temperatures rose then fell around the time of the first increase in wind speed before the trough passage (13/06-13/13).

As time series at these six stations illustrate, the sign of the temperature change associated with trough passage is not consistent between stations. Three of the six stations (UIL, GEG, FCA) have temperature falls associated with the trough passage ranging from $0.2^{\circ}$ to $2^{\circ} \mathrm{C}$ per hour. Temperature changes associated with the trough passage at the other stations range from increase at YYF, constant at YQL, and increase then decrease at GTF. That the signal is not consistent among stations is one of the challenges in analyzing western United States weather situations. Even among the three stations where the temperature falls, the modest temperature changes force us to question the validity of analyzing this feature as a surface front, if we define a front as a region of strong horizontal temperature gradient (e.g., Sanders and Doswell 1995). Consequently, we have not analyzed a front with this feature (Fig. 2).

Prior discussion of the nonfrontal nature of these mobile pressure troughs can be found in Hess and Wagner (1948), an extension of earlier work by Henry (1908, 1916). Their "moving pressure waves" responsible for lee cyclogenesis typically progressed at a speed of about $20 \mathrm{~m} \mathrm{~s}^{-1}\left(1000 \mathrm{~m}\right.$ day $\left.^{-1}\right)$, similar to the $22 \mathrm{~m} \mathrm{~s}^{-1}$ average speed computed for this case from Fig. 4b. Therefore, the pressure minima could not have been related to surface fronts, recognizing that the speed of surface fronts is closely related to a low-level advective wind speed, which is usually less than $20 \mathrm{~m} \mathrm{~s}^{-1}$. A similar argument was made by Sanders (1999b), in his discussion of the complex evolution of a cold front in the southwest United States.

Few research studies have examined the low-level structure and evolution of lower-tropospheric fronts in the complex topography of western North America. Baroclinic zones associated with upper-level features are often indistinct or absent below $700 \mathrm{mb}$ (Saucier 1955, p. 298); McClain and Danielsen (1955, p. 321) estimate that one-third to one-half of the landfalling Pacific cyclones may lack near-surface baroclinity. Williams (1972) asserts that cold fronts in the western United States often fail to move at the wind speed normal to the front in the cold air. Bonner (1961) found that lee cyclone formation occurred well ahead of the cold front of the parent surface cyclone. That the moving pressure waves are nonfrontal makes sense if one considers the difficulty in trying to move a surface air parcel through the complex terrain of the western United States, from the Pacific coast to the lee slopes, in a relatively short time (e.g., $12 \mathrm{~h}$ from landfall to redevelopment in this case). Mayr and McKee (1995, p. 1450) find that flow of low-level air out of the Intermountain West was prohibited $65 \%-92 \%$ of the time for a 3-month winter period. Furthermore, Lackmann et al. (1998) note that the transport of moisture from the Pacific Ocean below 800 $\mathrm{hPa}$ during a continental precipitation event is small 

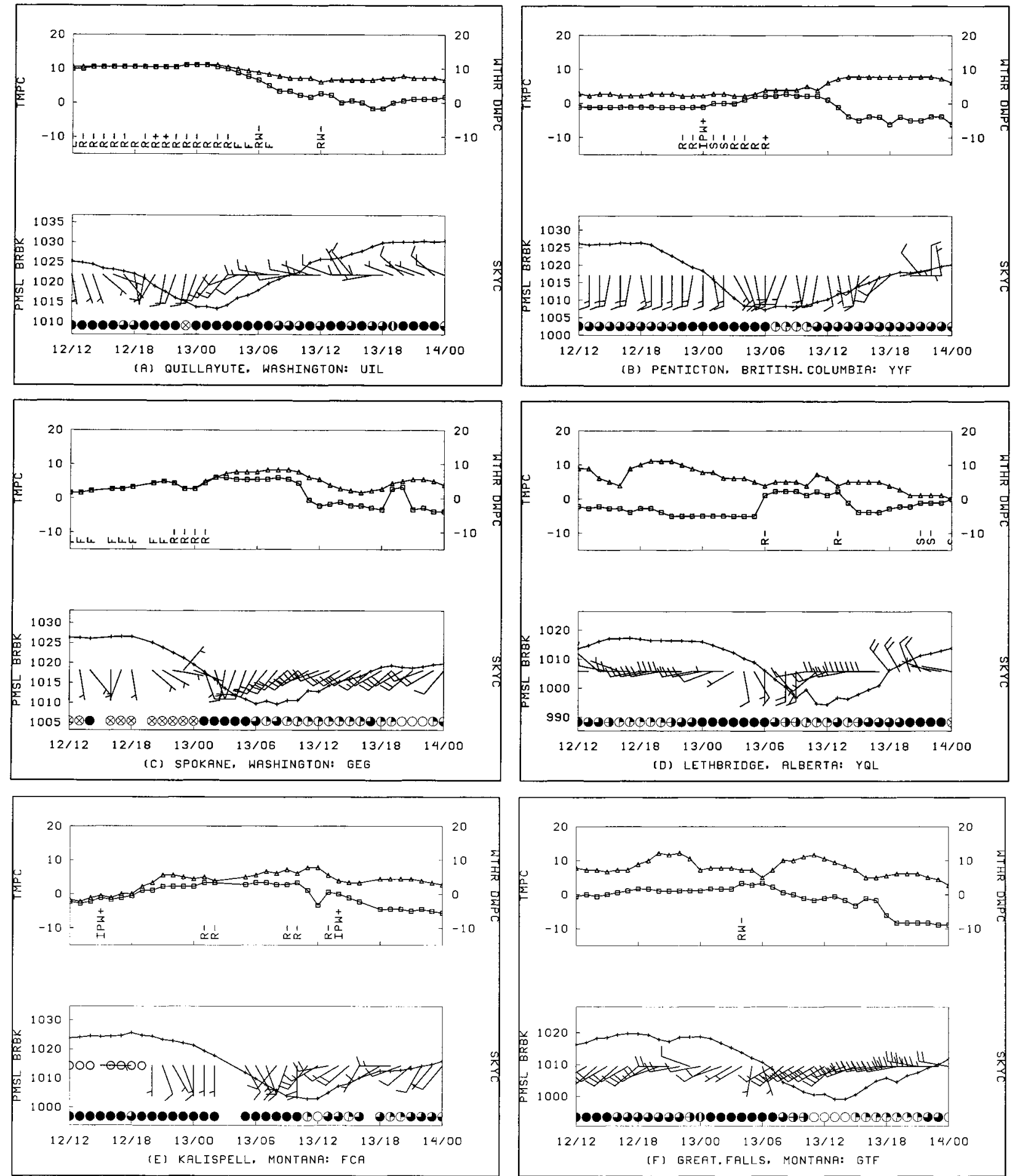

FIG. 7. Time series of surface parameters from 1200 UTC 12 Dec to 0000 UTC 14 Dec 1988 . (top) Temperature $\left({ }^{\circ} \mathrm{C}\right.$; triangles) and dewpoint temperature $\left({ }^{\circ} \mathrm{C}\right.$; squares); observed weather: $\mathrm{R}=$ rain, $\mathrm{F}=\mathrm{fog}, \mathrm{W}=$ showers, $\mathrm{S}=$ snow, $\mathrm{IP}=$ ice pellets, $+=$ heavy, $-=$ light. (bottom) Sea level pressure (hPa) and horizontal wind (pennant, full barb, and half barb denote 25, 5, and $2.5 \mathrm{~m} \mathrm{~s}^{-1}$, respectively). See Fig. 4, for station locations: (a) UIL, (b) YYF, (c) GEG, (d) YQL, (e) FCA, and (f) GTF. 
because of blocking by the Rocky Mountains. Coupled with the relatively weak baroclinity that landfalling cyclones often possess, tracking continuous baroclinic zones at the surface may not be feasible for all events, regardless of the density of surface observing stations. Further discussion of this point as it applies to operational surface analysis can be found in Hess and Wagner (1948, p. 17).

This case is additional evidence for the increasingly recognized fact that the surface wind shift or pressure trough does not necessarily have to coincide with the surface temperature change [see Schultz and Steenburgh (1999, p. 1109) and references within]. In a classical cold front, the arrival of cold, dense air in the lower troposphere is associated with concomitant surface pressure rises. Indeed, if the feature termed a cold front is a tropospheric-deep, baroclinic structure, then a pressure rise should accompany the temperature drop. In extreme cases of arctic frontal passages in the central plains, for example, pressure rises of several hectopascals (millibars) per hour can be observed. But, for typical troughs or weak fronts, the surface pressure changes associated with just the lower-tropospheric temperature changes may be overwhelmed by pressure changes due to other processes (i.e., height falls due to mobile pressure features aloft). This research suggests that further examinations of the variety of different processes that cause separation of the temperature gradient and the surface pressure trough are warranted.

Consequently, we question the applicability of analyzing this pressure minimum as a front on surface analyses. [As a contrasting example, the conceptual model of southern Alberta lee cyclogenesis by Palmén and Newton (1969, Fig. 11.16), for example, shows the progression of a surface front through western North America.] Analysts might be tempted to draw a front within the pressure trough, but frontal properties may not be present (e.g., Sanders and Doswell 1995; Sanders 1999a,b).

Recently, Sanders (1999a) proposed a classification scheme encompassing fronts (regions of strong temperature gradient and cyclonic vorticity), nonfrontal baroclinic zones (regions of strong temperature gradient, but little to no cyclonic vorticity), and nonfrontal troughs (or baroclinic troughs, regions of strong cyclonic vorticity, but little to no temperature gradient). We feel that Sanders's (1999a) term nonfrontal trough best describes the feature in this case. It is important to draw the distinction between these features because their dynamics may be entirely different. Thus, by drawing a line on a map that is customarily referred to as a front, certain properties of that feature become implicit. For example, by labeling a feature a cold front, the textbook cross section through a cold front pops into our minds, whether the feature has those properties or not. Understanding the structure and evolution of weather systems moving through the western United States and their effects on sensible weather changes (e.g., temperature, cloudiness, precipitation) will depend on challenging these textbook notions.

\section{Case study: Mesoscale model simulation}

To examine further the development of this lee cyclogenesis and the mobile pressure trough using high spatial and temporal resolution, a mesoscale model simulation of this event was performed. Section 3a describes the mesoscale model used to simulate the lee cyclogenesis, which is discussed in section $3 \mathrm{~b}$.

\section{a. Model description}

The Pennsylvania State University-National Center for Atmospheric Research (PSU-NCAR) Mesoscale Model 5 (MM5), a nonhydrostatic, primitive-equation, terrain-following coordinate model (Dudhia 1993; Grell et al. 1994), was employed to simulate the lee cyclogenesis. The simulation was initialized at 1200 UTC 12 December 1988, was ended at 1200 UTC 14 December 1988 , and featured 23 variably spaced terrain-following coordinate levels in the vertical. A domain with $30-\mathrm{km}$ horizontal grid spacing was nested within a domain with 90-km horizontal grid spacing using a two-way interactive mesh-refinement scheme. Precipitation processes were parameterized using an explicit-moisture scheme that includes prognostic equations for water vapor, cloud water, and rainwater; cloud water and rainwater are assumed to be cloud ice and snow if the temperature is below $0^{\circ} \mathrm{C}$ (Dudhia 1989; Grell et al. 1994, section 5.3.1.1). The Kain-Fritsch cumulus parameterization (Kain and Fritsch 1993) was used to represent subgridscale convective precipitation. Other parameterizations included a multilevel planetary boundary layer (Zhang and Anthes 1982) and a radiative upper boundary condition (Klemp and Durran 1983).

Four-dimensional data assimilation was used throughout the simulation on the $90-\mathrm{km}$ domain and during the first $12 \mathrm{~h}$ on the $30-\mathrm{km}$ domain. ${ }^{2}$ The assimilation technique (Stauffer and Seaman 1990) employs Newtonian nudging to relax the model simulation to gridded 12-h upper-level and 3-h surface analyses. To create the upper-level analyses, National Meteorological Center

\footnotetext{
${ }^{2}$ Initial simulations without four-dimensional data assimilation were performed, but were not successful. Departure in these initial simulations occurred $6 \mathrm{~h}$ later than that observed. Steenburgh and Mass (1994) also had difficulties with their MM4 (the hydrostatic predecessor to MM5) simulation of a different southern Alberta lee cyclogenesis event. Because their initial model simulation (MTS) deviated from reality, a second simulation (PLAINS) was performed to capture the remainder of the event, after departure had occurred (W. J. Steenburgh 1998, personal communication). These two situations are further evidence that numerical model simulations of lee cyclogenesis can be problematic, whether it be from initial-condition uncertainties, inadequate model resolution, or improper model physics (see section 1).
} 

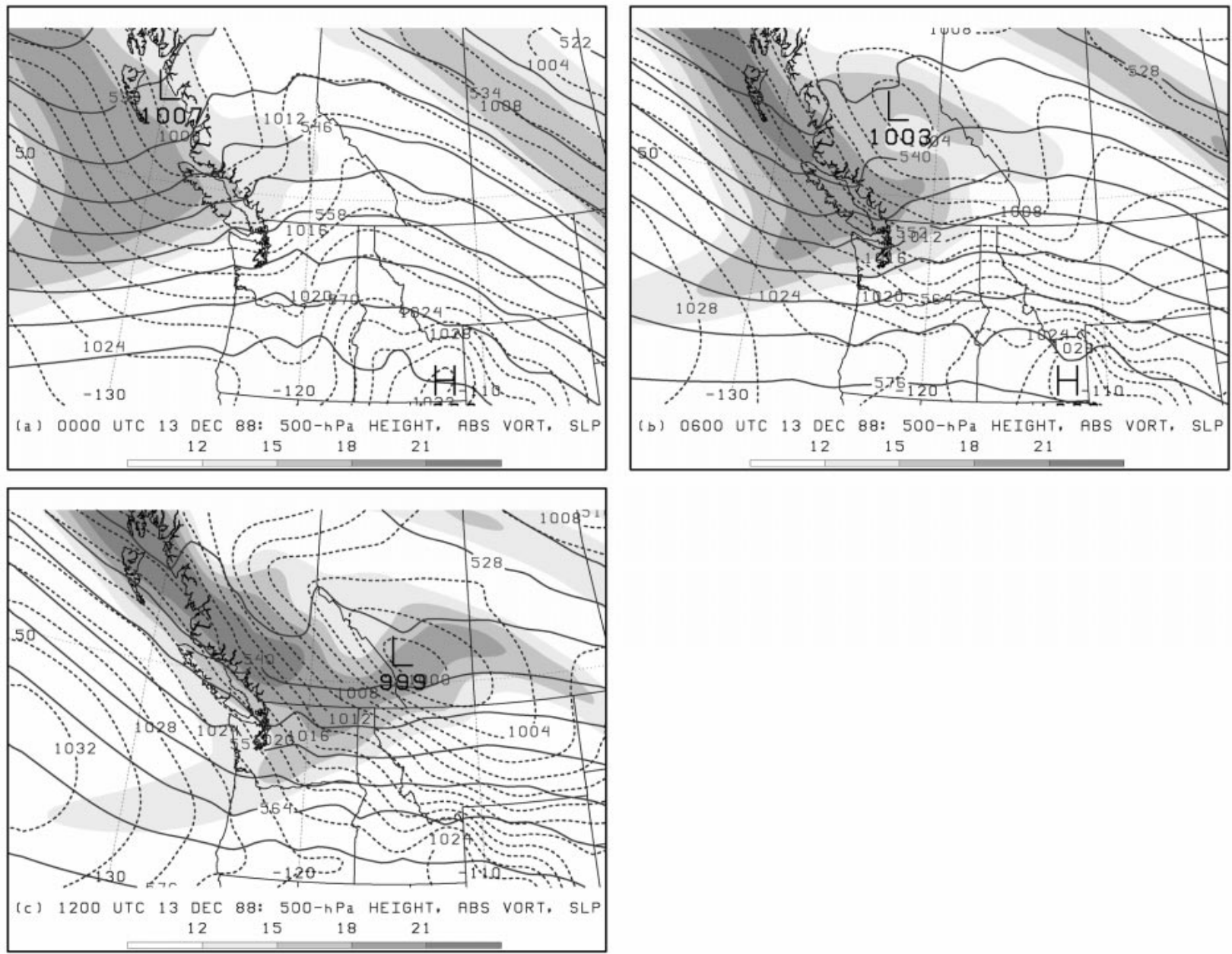

FIG. 8. Simulated sea level pressure from MM5 domain with 90-km horizontal grid spacing: 500-hPa geopotential height (solid lines every $6 \mathrm{dam}$ ), sea level pressure (dashed lines every $2 \mathrm{hPa}$ ), and absolute vorticity of total $500-\mathrm{hPa}$ wind $\left(10^{-5} \mathrm{~s}^{-1}\right.$, shaded according to scale): (a) 0000 UTC 13 Dec, (b) 0600 UTC 13 Dec, and (c) 1200 UTC 13 Dec 1988.

(NMC, now known as NCEP) analyses were interpolated to the model grid. Surface and upper-air observations were then incorporated into the analysis using a Cressman-type analysis scheme (Benjamin and Seaman 1985). After the removal of superadiabatic lapse rates below $500 \mathrm{hPa}$, the analysis was interpolated to the terrain-following coordinate system, and the integrated mean divergence was removed to avoid the production of spurious gravity waves. Three-hour surface analyses were generated similarly, with first-guess analysis fields provided by linear interpolation of 12-h NMC analyses. Lateral boundary conditions for the $90-\mathrm{km}$ domain were generated by linear interpolation of the 12-h analyses. Throughout this paper, only output from the domain with $90-\mathrm{km}$ horizontal grid spacing is displayed.

\section{b. Results}

In order to examine the quality of the simulation, we compare maps of simulated sea level pressure (Fig. 2) to those analyzed (Fig. 8) for three times: 13/00, 13/06, and $13 / 12$. At $13 / 00$, the simulated primary cyclone is about $7 \mathrm{hPa}$ shallower than that analyzed but is located in the proper place (cf. Figs. 2b and 8a). At 13/06, the simulation cannot resolve the multiple low centers present in the analysis, although the simulation is reasonably successful at locating the absolute minimum of central pressure over the Fraser River Valley (cf. Figs. 2c and $8 b$ ). The location and relative depth of the lee trough is also realistic (cf. Figs. 2c and 8b). By 13/12, the model was able to simulate the timing and location of the northwest-southeast-elongated low center as the cyclone departed the lee slopes of the mountains, although not as abruptly as in the analysis of the observations (cf. Figs. $2 \mathrm{f}$ and $8 \mathrm{c}$ ). As before, the analyzed central pressure was about $6 \mathrm{hPa}$ deeper than the model simulation. We would expect some difficulty in precisely simulating the location and intensity of the cyclone central pressure because the model terrain is smoother than the actual terrain and the sea level reduction schemes used by the model and the observations will not match perfectly. 
Such issues, however, cannot explain the 7-hPa error at $13 / 00$ when the cyclone is near sea level. Nevertheless, we believe that the simulation is of sufficient accuracy to be useful for diagnosis.

This simulation also provides some insight into the rapid evolution of the upper-level features between 0000 and 1200 UTC 13 December. Figure 8 shows the close relationship between the $500-\mathrm{hPa}$ vorticity maximum and the mobile surface low pressure center. In this paper, we use the model simulation to examine the feature aloft that appears to be responsible for the mobile surface cyclone.

\section{Diagnosis}

We suspect that the traveling pressure minimum at the surface is related to forcing from the mobile vorticity maximum aloft. In order to demonstrate this relationship, we calculate the forcing for height falls using the quasigeostrophic (QG) height-tendency equation partitioned into the differential thermal advection and the vorticity advection (section $4 \mathrm{~b}$ ). As shown by Barnes et al. (1996), however, applying QG diagnostics to mesoscale model data results in small-scale features that are unverifiable or model noise. Consequently, to examine such fields, filtering must be performed (section 4a). Filtering also has the beneficial result that the relatively small position and intensity errors of the simulated cyclone become relatively unimportant.

\section{a. Filtering methodology}

All QG diagnostics are calculated first, then filtered to maximize the numerical accuracy in the calculation of derivatives (e.g., Doswell and Caracena 1988). To produce a filtered field $f$ from a computed diagnostic field $F$, we apply a two-dimensional Gaussian filter at each point $\left(x_{0}, y_{0}\right)$ in the domain:

$$
f\left(x_{0}, y_{0}\right)=\frac{\sum_{x=1}^{N_{x}} \sum_{y=1}^{N_{y}} w\left(x, y ; x_{0}, y_{0}\right) F(x, y)}{\sum_{x=1}^{N_{x}} \sum_{y=1}^{N_{y}} w\left(x, y ; x_{0}, y_{0}\right)},
$$

where

$$
\begin{aligned}
& w\left(x, y ; x_{0}, y_{0}\right) \\
& \quad=\frac{1}{\pi \lambda^{2}} \exp \left\{-\frac{1}{\lambda^{2}}\left[\left(x-x_{0}\right)^{2}+\left(y-y_{0}\right)^{2}\right]\right\},
\end{aligned}
$$

$N_{x}$ is the number of grid points in the $x$ direction (80, for the $90-\mathrm{km}$ domain), $N_{y}$ is the number of grid points in the $y$ direction (50, for the $90-\mathrm{km}$ domain), and $\lambda$ is the weight parameter, the $e$-folding distance for the filter. In this case, $\lambda$ is set to $5 \sqrt{2}$, an $e$-folding distance of $636 \mathrm{~km}$. This value of $\lambda$ is somewhat conservative, but appropriate for the scales for which QG theory is strictly valid and for the resolution of the operational upper-air network over North America with an average spacing between stations of $400 \mathrm{~km}$. Different filters [the cowbell filter of Barnes et al. (1996) and the Gaussian filter (1)] and values of $\lambda(3 \sqrt{2}$ and $5 \sqrt{2}$ ) were tested and the results were qualitatively similar to the filter used in this study.

\section{b. Quasigeostrophic height-tendency diagnostics}

The QG height-tendency $(\chi=d \Phi / d t)$ equation (e.g., Bluestein 1992, p. 330) can be written

$$
\begin{aligned}
& \left(\nabla_{p}^{2}+\frac{f_{0}^{2}}{\sigma} \frac{\partial^{2}}{\partial p^{2}}\right) \chi \\
& =-\frac{f_{0}^{2}}{\sigma} \frac{\partial}{\partial p}\left[\frac{R}{p}\left(-\mathbf{V}_{g} \cdot \nabla_{p} T\right)\right]+\underbrace{f_{0}\left[-\mathbf{V}_{g} \cdot \nabla_{p}\left(\zeta_{g}+f\right)\right],} \\
& \text { differential thermal } \\
& \text { vorticity advection } \\
& \text { advection }
\end{aligned}
$$

where $\Phi$ is the geopotential height, $\boldsymbol{\nabla}_{p}=\mathbf{i} \partial / \partial x+\mathbf{j} \partial / \partial y$ measured on a constant-pressure surface, $f_{0}$ is the reference Coriolis parameter $\left(10^{-4} \mathrm{~s}^{-1}\right), f$ is the variable Coriolis parameter, $\sigma=-(\alpha / \theta) \partial \theta / \partial p$ is the static stability, $\alpha$ is specific volume, $\theta$ is potential temperature, $\mathbf{V}_{g}$ is geostrophic wind, $\zeta_{g}$ is geostrophic relative vorticity, $R$ is the universal gas constant, $p$ is pressure, and $T$ is temperature. The right-hand side of (3) consists of two forcing terms: differential thermal advection and vorticity advection, which, when positive (negative), force height falls (rises) or negative (positive) QG height tendencies.

At $13 / 00$, the forcing due to differential thermal advection at $500 \mathrm{hPa}$ (Fig. 9a) is weaker than and occurs slightly upstream of that due to the vorticity advection (Fig. 9b), so that their sum lies nearly over the surface cyclone (Fig. 9c). Forcing for height falls by vorticity advection is slightly southeast of the surface cyclone (Fig. 9b), suggesting the importance of the mobile shortwave trough to the movement of the surface cyclone. Indeed, an absolute-vorticity maximum was located upstream of the landfalling cyclone (Fig. 8a). An eastwest vertical cross section through these maxima shows that the forcing at $500 \mathrm{hPa}$ is representative of deep mid- to upper-tropospheric forcing, which is maximized at the tropopause (Fig. 9d).

Similar diagnostics at 13/06 and 13/12 show that the forcing for height falls due to differential thermal advection is smaller in magnitude and in horizontal extent than that due to the vorticity advection (cf. Fig. 10a with Fig. 10b and Fig. 11a with Fig. 11b). As at 13/00, the total forcing for height falls is roughly collocated with the surface cyclone and is representative of a deep mid- to upper-tropospheric structure (Figs. 10c,d and Figs. $11 \mathrm{c}, \mathrm{d})$. The southeastward movement of the forc- 

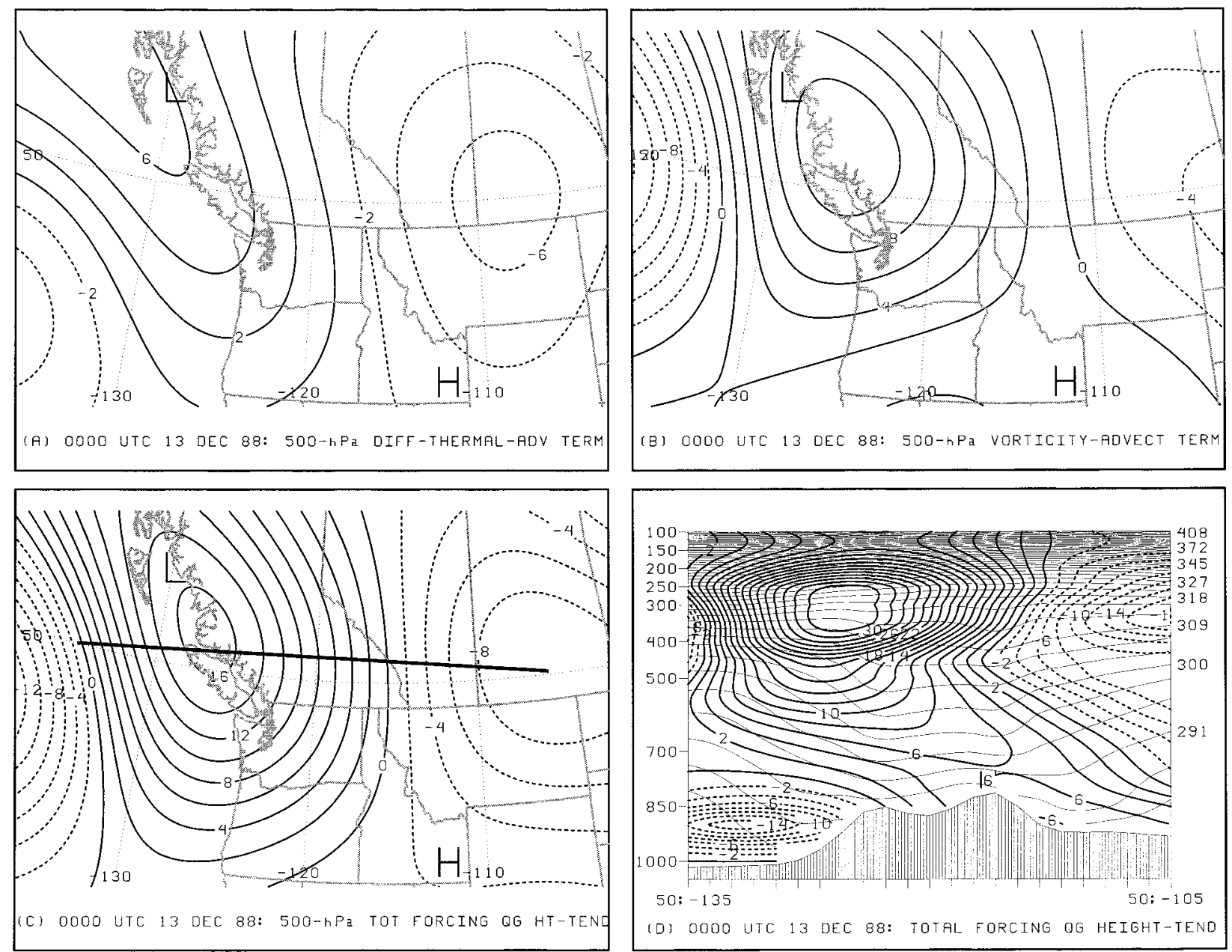

FIG. 9. Forcing for QG height tendency at 0000 UTC 13 Dec 1988 from MM5 domain with 90-km horizontal grid spacing; forcing for height falls (rises) are solid (dashed); L's and H's represent locations of sea level pressure maxima and minima: (a) 500-hPa forcing for QG height tendency from differential thermal advection term $\left(10^{-14} \mathrm{~s}^{-3}\right)$; (b) 500-hPa forcing for QG height tendency from vorticity advection term $\left(10^{-14} \mathrm{~s}^{-3}\right)$; (c) $500-\mathrm{hPa}$ total forcing for QG height tendency $\left(10^{-14} \mathrm{~s}^{-3}\right)$, location of cross section in (d) shown by thick solid line; (d) vertical cross section from $\left(50^{\circ} \mathrm{N}, 135^{\circ} \mathrm{W}\right)$ to $\left(50^{\circ} \mathrm{N}, 105^{\circ} \mathrm{W}\right)$ of total forcing for QG height tendency $\left(10^{-14} \mathrm{~s}^{-3}\right)$ and potential temperature (K, thin solid lines). Uncontoured values below $850 \mathrm{hPa}$ over the Pacific Ocean in (d) are attributed to a near-neutral layer (i.e., the static stability $\sigma$ is small, pushing the validity of QG theory).

ing after 13/06 is consistent with the southeastward movement of the bandpass-filtered pressure anomaly at the same time (cf. Figs. 10b,c and 11b,c and Figs. 6d-f.)

In this section, computations of the terms in the QG height-tendency equation illustrated the relationship of the surface pressure minimum to forcing from the mobile upper-level vorticity maximum. Although these diagnostics showed a close relationship, an exact relationship cannot be expected for three reasons. First, to obtain the complete forcing for surface height falls, the forcing terms at all levels, not just $500 \mathrm{hPa}$, must be integrated. As shown in the cross sections (Figs. 9d, $10 \mathrm{~d}$, and 11d), however, the forcing is deep throughout the mid- and upper troposphere, showing that a single level can be representative of a much deeper layer in these cases. Second, to obtain the actual QG height tendency at the surface, (3) would need to be solved ex- plicitly, which is beyond the scope of this paper. Finally, we would expect the computed QG height tendency to equal the actual height tendency only in the most ideal of cases (e.g., neglecting non-QG, diabatic, and orographic effects). Therefore, the QG height-tendency diagnostics illustrate that the forcing for the mobile pressure minima at the surface is associated with the advection of upper-level absolute vorticity in the 13 December 1988 case. This fact gives us confidence that tracking mobile pressure minima in other cases of lee cyclogenesis is useful for locating the forcing for height falls due to the upper-level vorticity maxima.

\section{Climatology}

In order to assess the frequency of occurrence of the evolution epitomized by this case, a climatology of 

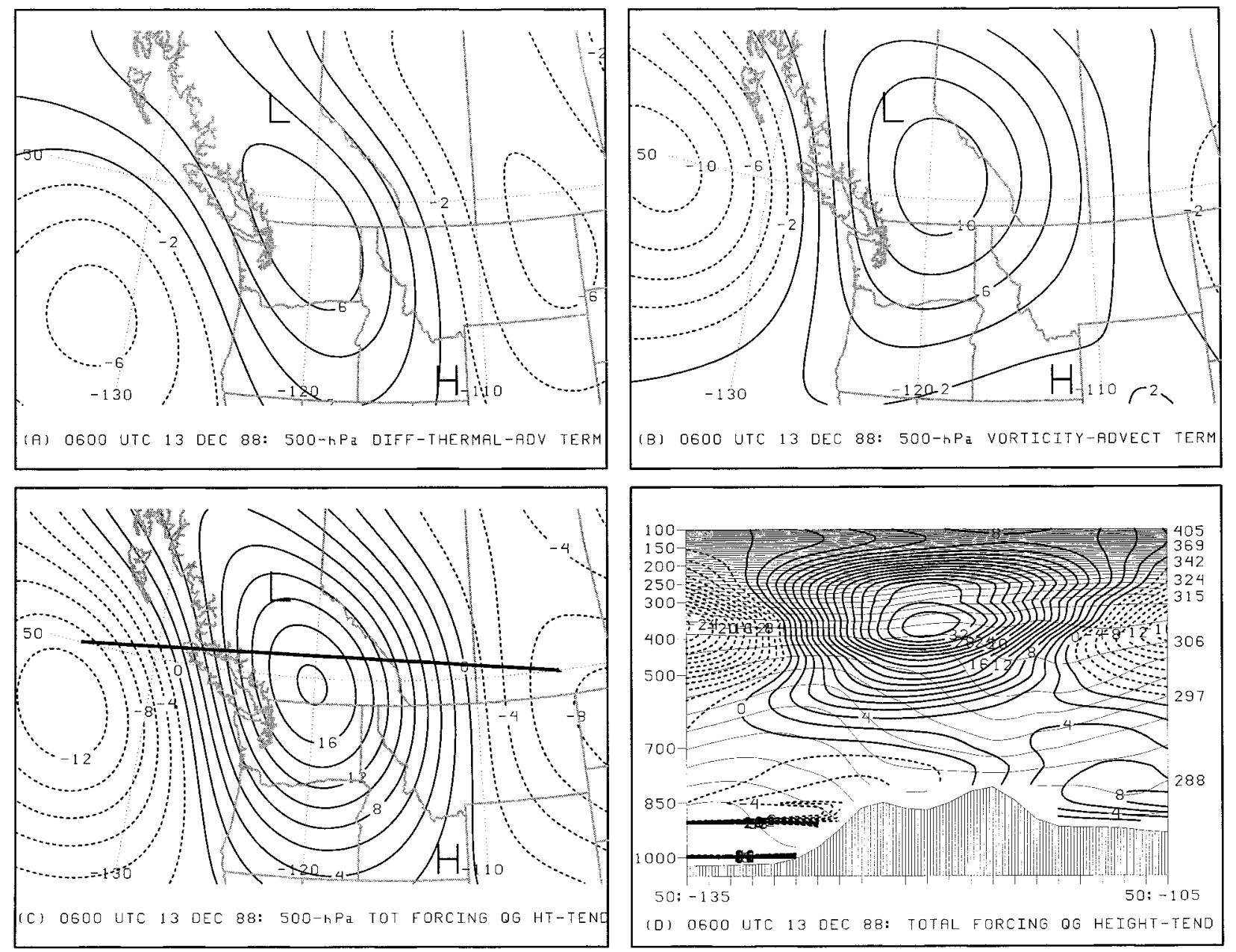

FIG. 10. As in Fig. 9 except for 0600 UTC 13 Dec 1988.

southern Alberta lee cyclones was compiled. The NMC 3-h North American surface analyses on microfilm were examined for lee cyclones in November, December, January, and February for the five winters 1985-86 through 1989-90. This period was selected to minimize the number of surface analyses with automated isobars to avoid the perceived degradation in the quality of the analyses of sea level pressure (e.g., Bosart 1989). An event was defined when a preexisting lee trough or cyclone in southern Alberta $\left(49^{\circ}-55^{\circ} \mathrm{N}\right)$ moved eastward away from the lee slopes of the mountains past $110^{\circ} \mathrm{W}$. No minimum duration or central pressure criteria were applied, although most events became well-developed cyclones over eastern North America.

One hundred and eleven events were identified, averaging about 22 events per 4-month winter period or about one event per 6 days. To ascertain the possibility that departure was associated with a mobile upper-level vorticity maximum, the sea level pressure tendency at Spokane, Washington (GEG) was characterized. Spokane was selected for three reasons. First, as noted by Atallah and Bosart (1998), a preferred pathway for 700-
$\mathrm{hPa}$ vorticity maxima through the mountains of western North America is through the Columbia River Valley. Vorticity maxima that make it into eastern Washington by this route, hence, will pass very near Spokane. Thus, Spokane is ideally located for experiencing the effects of mobile mid- to upper-tropospheric vorticity maxima associated with lee cyclogenesis. Second, Spokane lies on a relatively broad plain in eastern Washington and should be relatively unaffected by transient orographic pressure disturbances. Third, Spokane is a reliable firstorder station, plotted on nearly every NMC 3 -h surface map. When maps at two or more times reported the same minimum pressure value at Spokane, the time with a pressure check in the pressure-tendency notation was selected. If no pressure check was reported, then the later time was selected. For the 13 December 1988 case, Spokane reported a minimum pressure at 0600 UTC (Fig. 7c), $6 \mathrm{~h}$ before departure at 1200 UTC 13 December (Figs. 2e,f).

For $69(62 \%)$ of the 111 events, Spokane reported a minimum in pressure 3-9 $\mathrm{h}$ (one to three surface maps) before the event (Fig. 12). Nineteen events (17\%) were 

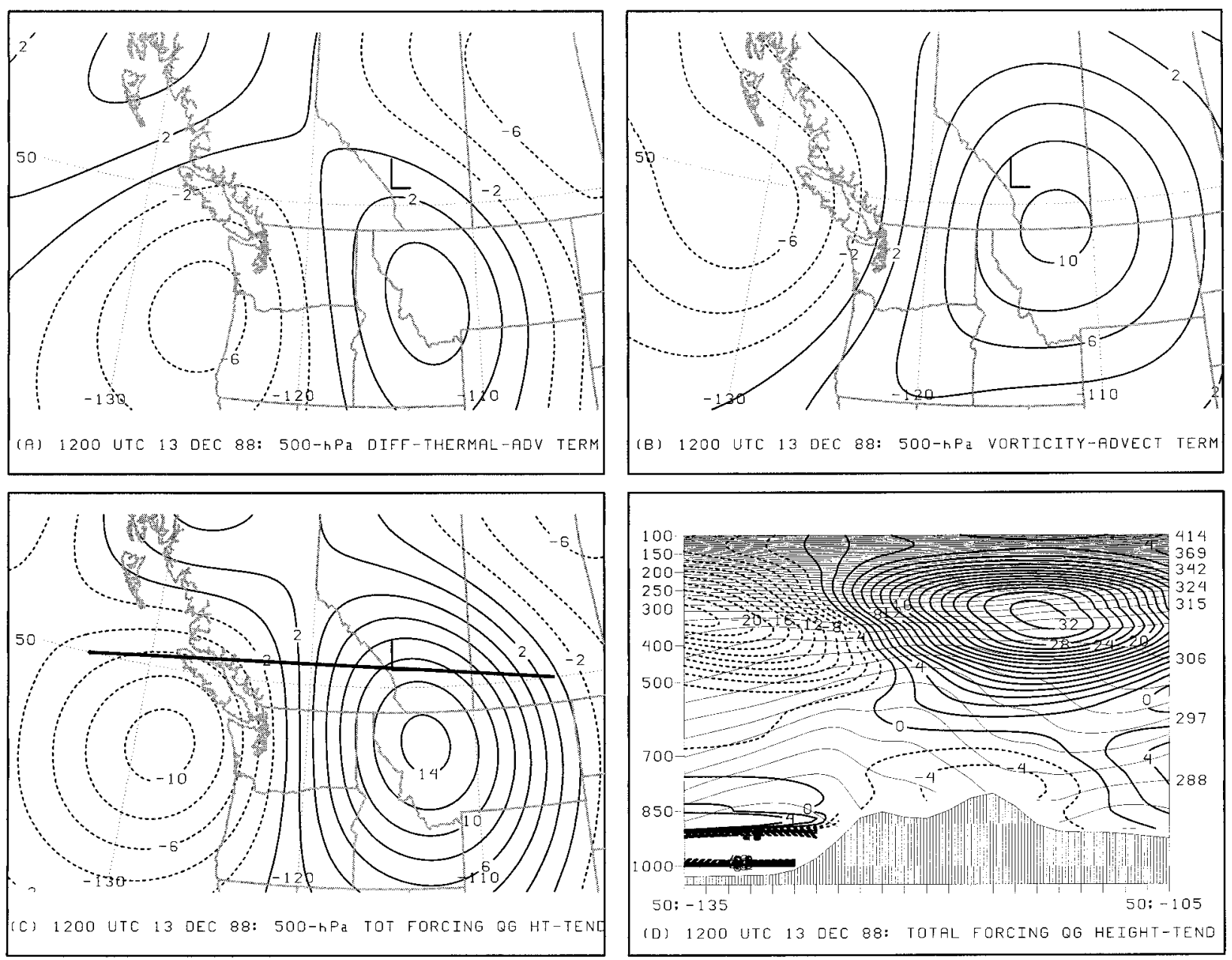

FIG. 11. As in Fig. 9 except for 1200 UTC 13 Dec 1988.

characterized by a pressure minima greater than $9 \mathrm{~h}$ prior to the event. These events were associated with relatively weak flow aloft or a large change in the $500-\mathrm{hPa}$ synoptic-scale flow, such as a building ridge. Thus, the relationship between the pressure minimum at Spokane and the lee cyclogenesis in these cases may be ambiguous and would not satisfy our criteria for validating our hypothesis. Twelve events (11\%) (labeled as "falling" in Fig. 12) were associated with falling pressure that continued beyond departure. These events were often characterized by a large change in the $500-\mathrm{hPa}$ synoptic-scale flow, such as a collapsing large-scale ridge over western North America. Finally, three events (3\%) did not have a clear signature in the 3 -h pressure change and so were classified as "other."

These results suggest that the majority of cyclones that move away from the mountains are associated with mobile pressure-change patterns upstream of the lee slopes. Unfortunately, large-scale pressure rises/falls may mask pressure troughs associated with short-wavetrough passage. Thus, the relative success in following the pressure minimum for the 12-13 December 1988 event is likely attributable to the relatively quiescent large-scale flow evolution (Fig. 8) and the lack of large changes in near-surface air masses over western North America (e.g., Fig. 2). In preparing this climatology, the following additional relationships were apparent. 1) The presence of an arctic high in the lee of the mountains inhibits departure of a lee trough. 2) Lee cyclones in northwesterly 500-mb flow tend to move southeastward along lee slopes, rather than moving eastward. 3) Lee cyclones in strong zonal flow are likely to depart more quickly (tending to occur in the 3-6-h categories in Fig. 12). 4) If the 500-hPa flow aloft is poorly defined (slowmoving cutoff or closed low), movement of surface pressure troughs may not be well defined. These relationships, therefore, should be considered in adapting this strategy to individual cases.

Finally, to assess the impact of hazardous weather from these events, we employ Storm Data. Although we recognize the inherent limitations of the Storm Data database (e.g., Branick 1997), we note its importance as an expeditious way to assess the potential severity of these events. Eighty-four (76\%) of the 111 events 


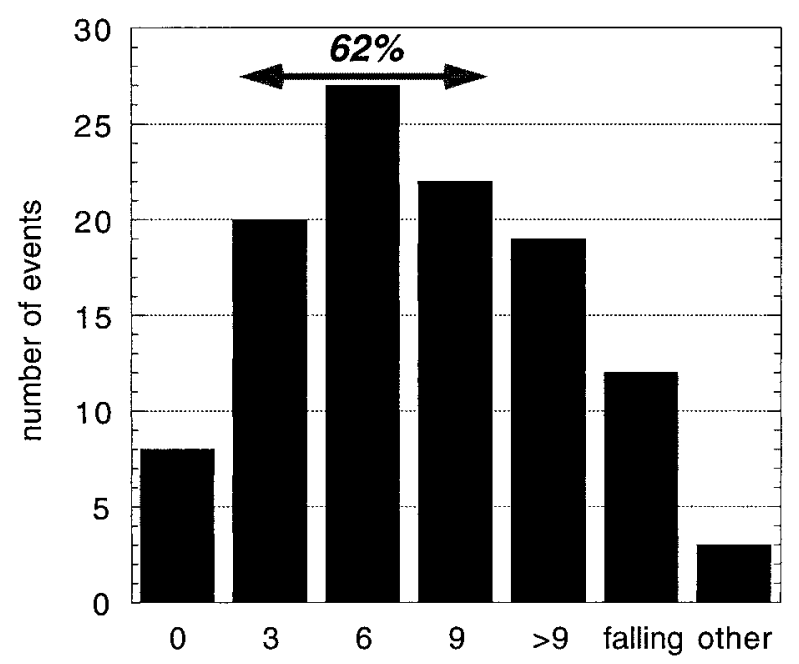

hours between pressure minimum at Spokane and lee cyclone movement away from mountains

FIG. 12. Distribution of the time in hours between the observed pressure minimum at GEG and lee cyclone movement away from the mountains (i.e., departure for 111 southern Alberta lee cyclogenesis events. Times determined from 3-h NMC surface analyses. "Falling" represents a time series of pressure at Spokane that does not reach a minimum because it falls monotonically. "Other" represents a time series of pressure that is difficult to classify as a pressure minimum or falling.

were associated with reports of hazardous weather in Washington, Idaho, Montana, Wyoming, or the Dakotas. M. L. Branick (1998, personal communication), however, notes that eastern Montana and the Cascades of Washington have a paucity of Storm Data reports relative to surrounding areas. Categorizing these reports by state shows that the overwhelming majority of reports in Storm Data associated with these lee cyclogenesis events were of strong winds or heavy snow (Fig. 13). Strong winds were reported most frequently in the lee of the Rockies in Montana and Wyoming, whereas heavy snow was reported most frequently in Wyoming and Idaho. Blizzard conditions were reported most frequently in Idaho and the Dakotas. Mixed precipitation reports generally occurred in the Dakotas and Wyoming. Flooding, heavy rains, and convective phenomena were typically reported in Washington and Idaho. This climatology, however, does not take into account reports from Canada (e.g., British Columbia, Alberta) or farther east and south in the United States.

\section{Conclusion}

This article presents the evolution of the lee cyclogenesis event of 13 December 1988, when a preexisting lee trough in southern Alberta persisted for about $11 \mathrm{~h}$ before rapidly developing into a mobile midlatitude cyclone, the cyclone center apparently jumping $300 \mathrm{~km}$ in $1 \mathrm{~h}$. The movement of the cyclone away from the mountains favored the development of strong chinook

\section{STORM-DATA REPORTS BY STATE FOR CLIMATOLOGY OF 111 SOUTHERN-ALBERTA LEE CYCLONES}

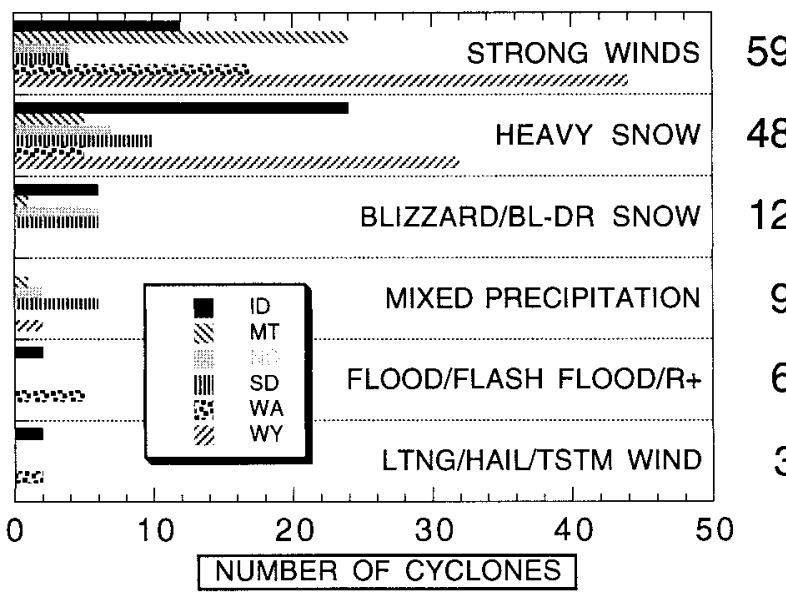

FIG. 13. Number of lee cyclones with Storm Data reports by state. ID = Idaho; MT = Montana ND = North Dakota; SD = South Dakota; WA = Washington; WY $=$ Wyoming. "bl-dr snow" represents blowing and drifting snow; "mixed precipitation" represents sleet and/or freezing rain; " $\mathrm{R}+$ " represents heavy rain; "ltng/hail/ tstm wind" represents lightning, hail, and/or thunderstorm wind. Numbers along right side of plot indicate the number of unique storms in each category (i.e., a single storm could have strong winds reported in two or more states).

winds. Because numerical models have difficulty forecasting lee cyclogenesis, observational methodologies were explored to anticipate the departure of the lee trough from the mountains. These methods are based upon tracking surface pressure minima (troughs) across the complex terrain using time series at individual surface stations and bandpass filtering. In the event presented in this article, a pressure minimum could be tracked from the Pacific coast of North America to the lee of the Rocky Mountains. The arrival of the pressure minimum to the lee slopes of the Rockies was coincident with the movement of the lee trough away from the mountains (departure), results in agreement with earlier studies. A climatology of lee cyclogenesis suggested that the majority of these events could be anticipated hours in advance by watching for these pressure minima in time series at upstream stations. Therefore, this method provides a potential way to improve short-term forecasts of departure when numerical models begin to deviate from reality.

These traveling pressure minima are similar to the "moving pressure waves" described by Hess and Wagner (1948). This article extends their work by showing the utility of this feature to a case of Rocky Mountain lee cyclogenesis and demonstrating that the reason for the migratory pressure trough is the forcing from the upper-level vorticity maximum responsible for lee cyclogenesis. Bandpass-filtered pressure fields provide support for results from idealized modeling studies that show the baroclinic wave moving eastward through the 
complex topography. Pressure change maps and bandpass-filtered fields can be easily computed in the modernized weather service forecast offices. Such diagnostic tools can help forecasters evaluate the validity of numerical forecasts of lee cyclogenesis.

Also, in accord with Hess and Wagner (1948), the mobile pressure trough over western North America does not resemble a front, but a nonfrontal trough (Sanders 1999a). Analysts should consider carefully whether a front should be associated with each landfalling cyclone and whether the ingrained habit of frontal continuity in time (e.g., Sanders and Doswell 1995, p. 507) should apply, particularly for western North American weather systems (see also, Williams 1972). Once lee cyclones move onto the central plains, they may develop new fronts or affix preexisting baroclinic zones already present in central North America, developing structures similar to those documented by Hobbs et al. (1990, 1996), Keshishian et al. (1994), and Steenburgh and Mass (1994).

Finally, we suggest that this methodology of tracking pressure minima can be useful for tracking the forcing aloft in other regions of complex terrain besides southern Alberta. Another maximum in cyclogenesis occurs in the lee of the Colorado Rockies (see cyclogenesis references in section 1). The typical path of the forcing aloft comes across the intermountain region and southwest United States (e.g., Hovanec and Horn 1975; Achtor and Horn 1986), regions of complex terrain. Also, cyclogenesis occurs in the lee of the Alps. Data from the Mesoscale Alpine Programme (http://www.map2. ethz.ch/) could be used to test this methodology. Given the emphasis on future United States Weather Research Program (USWRP) efforts to understand the interaction of weather systems with coastal and inland topography (Rotunno et al. 1996; Smith et al. 1997), this methodology may prove to possess considerable generality.

Acknowledgments. We are deeply indebted to the following individuals for their contributions to this work: Jim Steenburgh and David Stensrud for their assistance using MM5, Charlie Crisp for alerting us to the existence of Waters (1970), Katherine Day (NOAA Library, Boulder, Colorado) for performing an extensive literature search, Fedor Mesinger and Jamie Kousky for forwarding references on verification of the Eta Model, Fernando Caracena for providing the cowbell filter code, and John Brown, Roger Edwards, Eric Hoffman, and Keith Meier for their insights into western United States weather analysis issues. Charlie Crisp, Robert Maddox, Tom Matejka, Fred Sanders, Brad Smull, Jim Steenburgh, Steve Weiss, and an anonymous reviewer provided valuable comments on earlier versions of this manuscript.

We are grateful to the Data Support Section of the Scientific Computing Division of NCAR and the National Climatic Data Center for data used in this study, the Storm Prediction Center for access to their archives of NMC maps on microfilm, and the Mesoscale and Microscale Meteorology Division of NCAR for their support of MM5. Much of this research was conducted while the first author was a National Research Council Postdoctoral Research Associate at the National Severe Storm Laboratory.

\section{REFERENCES}

Achtor, T. H., and L. H. Horn, 1986: Spring season Colorado cyclones. Part I: Use of composites to relate upper and lower tropospheric wind fields. J. Climate Appl. Meteor., 25, 732-743.

Alexander, G. D., and G. S. Young, 1990: The use of quantitative surface cyclone characteristics to determine systematic departures from mean Nested Grid Model forecast errors. Natl. Wea. Dig., 15 (2), 6-12.

Atallah, E. H., and L. F. Bosart, 1998: Preferential storm pathways and trough structure through western North America: A climatology and case studies. Preprints, 16th Conf. on Weather Analysis and Forecasting, Phoenix, AZ, Amer. Meteor. Soc., 104105.

Bannon, P. R., 1992: A model of Rocky Mountain lee cyclogenesis. J. Atmos. Sci., 49, 1510-1522.

Barnes, S. L., F. Caracena, and A. Marroquin, 1996: Extracting synoptic-scale diagnostic information from mesoscale models: The Eta model, gravity waves, and quasigeostrophic diagnostics. Bull. Amer. Meteor. Soc., 77, 519-528.

Bates, G. T., 1990: A case study of the effects of topography on cyclone development in the western United States. Mon. Wea. Rev., 118, 1808-1825.

Benjamin, S. G., and N. L. Seaman, 1985: A simple scheme for objective analysis in curved flow. Mon. Wea. Rev., 113, 11841198.

Bluestein, H. B., 1992: Synoptic-Dynamic Meteorology in Midlatitudes. Vol. I, Principles of Kinematics and Dynamics, Oxford University Press, $431 \mathrm{pp}$.

_ 1993: Synoptic-Dynamic Meteorology in Midlatitudes. Vol. II, Observations and Theory of Weather Systems, Oxford University Press, $594 \mathrm{pp}$

Bonner, W. D., 1961: Development processes associated with the formation and movement of an Alberta cyclone. Tech. Rep. 4, Grant NSF-G6353, Dept. Meteorology, University of Chicago, 40 pp. [Available from Dept. of Geophysical Sciences, University of Chicago, 5743 S. Ellis Ave., Chicago, IL 60637.]

Bosart, L. F., 1989: Automation: Has its time really come? Wea. Forecasting, 4, 271.

Bowie, E. H., and R. H. Weightman, 1914: Types of storms of the United States and their average movements. Mon. Wea. Rev. (Suppl. 1), 3-37, plus 114 charts.

Branick, M. L., 1997: A climatology of significant winter-type weather events in the contiguous United States, 1982-94. Wea. Forecasting, 12, 193-207.

Brown, J. M., and E. J. Szoke, 1994: Evaluation of model utility in predicting snowstorms in eastern Colorado. Preprints, 10th Conf. on Numerical Weather Prediction, Portland, OR, Amer. Meteor. Soc., 138-140.

Buzzi, A., A. Speranza, S. Tibaldi, and E. Tosi, 1987: A unified theory of orographic influences upon cyclogenesis. Meteor. Atmos. Phys., 36, 91-107.

Carlson, T. N., 1961: Lee-side frontogenesis in the Rocky Mountains. Mon. Wea. Rev., 89, 163-172.

Chung, Y.-S., K. D. Hage, and E. R. Reinelt, 1976: On lee cyclogenesis and airflow in the Canadian Rocky Mountains and the east Asian Mountains. Mon. Wea. Rev., 104, 879-891.

Colucci, S. J., and L. F. Bosart, 1979: Surface anticyclone behavior in NMC prediction models. Mon. Wea. Rev., 107, 377-394.

Davis, C. A., 1997: The modification of baroclinic waves by the Rocky Mountains. J. Atmos. Sci., 54, 848-868. 
Demirtas, M., and A. J. Thorpe, 1999: Sensitivity of short-range weather forecasts to local potential vorticity modifications. Mon. Wea. Rev., 127, 922-939.

Doswell, C. A., III, 1977: Obtaining meteorologically significant surface divergence fields through the filtering property of objective analysis. Mon. Wea. Rev., 105, 885-892.

— sampled vector point functions. J. Atmos. Sci., 45, 242-253.

Dudhia, J., 1989: Numerical study of convection observed during the Winter Monsoon Experiment using a mesoscale two-dimensional model. J. Atmos. Sci., 46, 3077-3107.

- 1993: A nonhydrostatic version of the Penn State-NCAR mesoscale model: Validation tests and simulation of an Atlantic cyclone and cold front. Mon. Wea. Rev., 121, 1493-1513.

Durran, D. R., 1986: Mountain waves. Mesoscale Meteorology and Forecasting, P. S. Ray, Ed., Amer. Meteor. Soc., 472-492.

Grell, G. A., J. Dudhia, and D. R. Stauffer, 1994: A description of the fifth-generation Penn State/NCAR Mesoscale Model (MM5). NCAR Tech. Note NCAR/TN-398+STR, 138 pp. [Available from NCAR, P.O. Box 3000, Boulder, CO 80307-3000.]

Grumm, R. H., 1993: Characteristics of surface cyclone forecasts in the aviation run of the Global Spectral Model. Wea. Forecasting, $\mathbf{8}, 87-112$.

— , and A. L. Siebers, 1989: Systematic surface cyclone errors in NMC's Nested Grid Model November 1988-January 1989. Wea. Forecasting, 4, 246-252.

$\longrightarrow$, and _ 1990: Systematic model forecast errors of surface cyclones in the NGM and AVN, January 1990. Wea. Forecasting, 5, 672-682.

— , R. J. Oravec, and A. L. Siebers, 1992: Systematic model forecast errors of surface cyclones in NMC's Nested-Grid Model, December 1988 through November 1990. Wea. Forecasting, 7, $65-87$.

Henry, A. J., 1908: Accidental variations in atmospheric pressure in the United States. Mon. Wea. Rev., 36, 53-56.

— 1916: Auxiliary pressure-change charts. Weather Forecasting in the United States, A. J. Henry et al., Eds., U.S. Government Printing Office, 77-91.

Hess, S. L., and H. Wagner, 1948: Atmospheric waves in the northwestern United States. J. Meteor., 5, 1-19.

Hobbs, P. V., J. D. Locatelli, and J. E. Martin, 1990: Cold fronts aloft and the forecasting of precipitation and severe weather east of the Rocky Mountains. Wea. Forecasting, 5, 613-626.

,-- , and -1996 : A new conceptual model for cyclones generated in the lee of the Rocky Mountains. Bull. Amer. Meteor. Soc., 77, 1169-1178.

Hovanec, R. D., and L. H. Horn, 1975: Static stability and the 300 $\mathrm{mb}$ isotach field in the Colorado cyclogenetic area. Mon. Wea. Rev., 103, 628-638.

Huschke, R. E., Ed., 1959: Glossary of Meteorology. Amer. Meteor. Soc., $638 \mathrm{pp}$.

Hutchinson, T. A., 1995: An analysis of NMC's Nested Grid Model forecasts of Alberta clippers. Wea. Forecasting, 10, 632-641.

Junker, N. W., J. E. Hoke, and R. H. Grumm, 1989: Performance of NMC's regional models. Wea. Forecasting, 4, 368-390.

Kain, J. S., and J. M. Fritsch, 1993: Convective parameterization for mesoscale models: The Kain-Fritsch scheme. The Representation of Cumulus Convection in Numerical Models, Meteor. Monogr., No. 46, Amer. Meteor. Soc., 165-170.

Kapela, A. F., P. W. Leftwich, and R. Van Ess, 1995: Forecasting the impacts of strong wintertime post-cold front winds in the northern plains. Wea. Forecasting, 10, 229-244.

Keshishian, L. G., L. F. Bosart, and W. E. Bracken, 1994: Inverted troughs and cyclogenesis over interior North America: A limited regional climatology and case studies. Mon. Wea. Rev., 122, 565-607.

Klemp, J. B., and D. R. Durran, 1983: An upper boundary condition permitting internal gravity wave radiation in numerical mesoscale models. Mon. Wea. Rev., 111, 430-444.

Kousky, J. V., and R. H. Grumm, 1993a: Preliminary evaluation of
NMC's step mountain Eta Model forecasts of surface cyclones and anticyclones. Postprints, Third National Heavy Precipitation Workshop, Pittsburgh, PA, NOAA Tech. Memo. NWS ER-87, 267-274.

$\longrightarrow$, and —_ 1993b: An evaluation of NMC's regional forecast models. Preprints, 13th Conf. on Weather Analysis and Forecasting, Vienna, VA, Amer. Meteor. Soc., 125-128.

Lackmann, G. M., and J. R. Gyakum, 1999: Heavy cold-season precipitation in the northwestern United States: Synoptic climatology and an analysis of the flood of 17-18 January 1986. Wea. Forecasting, 14, 687-700.

— , L. F. Bosart, and D. Keyser, 1996: Planetary- and synopticscale characteristics of explosive wintertime cyclogenesis over the western North Atlantic Ocean. Mon. Wea. Rev., 124, 26722702.

— , J. R. Gyakum, and R. Benoit, 1998: Moisture transport diagnosis of a wintertime precipitation event in the Mackenzie River basin. Mon. Wea. Rev., 126, 668-691.

Leary, C., 1971: Systematic errors in operational National Meteorological Center primitive-equation surface prognoses. Mon. Wea. Rev., 99, 409-413.

Locatelli, J. D., J. M. Sienkiewicz, and P. V. Hobbs, 1989: Organization and structure of clouds and precipitation on the midAtlantic coast of the United States. Part I: Synoptic evolution of a frontal system from the Rockies to the Atlantic Coast. $J$. Atmos. Sci., 46, 1327-1348.

Longley, R. W., 1967: The frequency of winter chinooks in Alberta. Atmosphere, 5, 4-16.

Mass, C. F., W. J. Steenburgh, and D. M. Schultz, 1991: Diurnal surface-pressure variations over the continental United States and the influence of sea level reduction. Mon. Wea. Rev., 119, $2814-2830$.

Mayr, G. J., and T. B. McKee, 1995: Observations of the evolution of orogenic blocking. Mon. Wea. Rev., 123, 1447-1464.

McClain, E. P., 1960: Some effects of the western Cordillera of North America on cyclonic activity. J. Meteor., 17, 104-115.

_ , and E. F. Danielsen, 1955: Zonal distribution of baroclinity for three Pacific storms. J. Meteor., 12, 314-323.

Mesinger, F., R. L. Wobus, and M. E. Baldwin, 1996: Parameterization of form drag in the Eta Model at the National Centers for Environmental Prediction. Preprints, 11th Conf. on Numerical Weather Prediction, Norfolk, VA, Amer. Meteor. Soc., 324-326.

Mullen, S. L., and B. B. Smith, 1990: An analysis of sea-level cyclone errors in NMC's Nested Grid Model (NGM) during the 198788 winter season. Wea. Forecasting, 5, 433-447.

- , and -1993 : The dependence of short-range surface cyclone forecasts on the large-scale circulation: A preliminary assessment. Wea. Forecasting, 8, 235-247.

Newton, C. W., 1956: Mechanisms of circulation change during a lee cyclogenesis. J. Meteor., 13, 528-539.

Nielsen, J. W., and R. M. Dole, 1992: A survey of extratropical cyclone characteristics during GALE. Mon. Wea. Rev., 120, 1156-1167.

NOAA, 1988: Storm Data. Vol. 30, No. 12, 14-24.

Nkemdirim, L. C., 1996: Canada's chinook belt. Int. J. Climatol., 16, 441-462.

Oard, M. J., 1993: A method for predicting chinook winds east of the Montana Rockies. Wea. Forecasting, 8, 166-180.

Osmond, H. L., 1941: The chinook wind east of the Canadian Rockies. Can. J. Res., 19A, 57-66.

Palmén, E., and C. W. Newton, 1969: Atmospheric Circulation Systems. Academic Press, 603 pp.

Pauley, P. M., 1998: An example of uncertainty in sea level pressure reduction. Wea. Forecasting, 13, 833-850.

Petterssen, S., 1956: Weather Analysis and Forecasting. Vol. 1, Motion and Motion Systems, 2d ed., McGraw-Hill, 428 pp.

Pierrehumbert, R. T., 1986: Lee cyclogenesis. Mesoscale Meteorology and Forecasting, P. S. Ray, Ed., Amer. Meteor. Soc., 493-515.

Rotunno, R., and Coauthors, 1996: Coastal meteorology and oceanography: Report of the Third Prospectus Development Team of 
the U.S. Weather Research Program to NOAA and NSF. Bull. Amer. Meteor. Soc., 77, 1578-1585.

Sanders, F., 1988: Life history of mobile troughs in the upper westerlies. Mon. Wea. Rev., 116, 2629-2648.

_ 1999a: A proposed method of surface map analysis. Mon. Wea. Rev., 127, 945-955.

- 1999b: A short-lived cold front in the southwestern United States. Mon. Wea. Rev., 127, 2395-2403.

— ysis. Bull. Amer. Meteor. Soc., 76, 505-521.

Saucier, W. J., 1955: Principles of Meteorological Analysis. The University of Chicago Press, $438 \mathrm{pp}$.

Schultz, D. M., and C. A. Doswell III, 1999: Conceptual models of upper-level frontogenesis in south-westerly and north-westerly flow. Quart. J. Roy. Meteor. Soc., 125, 2535-2562.

—, and W. J. Steenburgh, 1999: The formation of a forward-tilting cold front with multiple cloud bands during Superstorm 1993. Mon. Wea. Rev., 127, 1108-1124.

Smith, B. B., and S. L. Mullen, 1993: An evaluation of sea level cyclone forecasts produced by NMC's Nested-Grid Model and Global Spectral Model. Wea. Forecasting, 8, 37-56.

Smith, R., and Coauthors, 1997: Local and remote effects of mountains on weather: Research needs and opportunities. Bull. Amer. Meteor. Soc., 78, 877-892.

Stauffer, D. R., and N. L. Seaman, 1990: Use of four-dimensional data assimilation in a limited-area mesoscale model. Part I: Experiments with synoptic-scale data. Mon. Wea. Rev., 118, 12501277
Steenburgh, W. J., and C. F. Mass, 1994: The structure and evolution of a simulated Rocky Mountain lee trough. Mon. Wea. Rev., 122, 2740-2761.

- , and - 1996: Interaction of an intense extratropical cyclone with coastal orography. Mon. Wea. Rev., 124, 1329-1352.

Stewart, R. E., and Coauthors, 1995: Winter storms over Canada. Atmos.-Ocean, 33, 223-247.

Walker, D. R., and R. E. Davis, 1995: Error climatology of the 80wave Medium-Range Forecast model. Wea. Forecasting, 10, 545-563.

Waters, A. W., 1970: Forecasting gusty surface winds in the continental United States. Air Weather Service Tech. Rep. 219, 74 pp. [Available from Air Force Weather Agency, Scott Air Force Base, IL 62225.]

Whittaker, L. M., and L. H. Horn, 1984: Northern Hemisphere extratropical cyclone activity for four mid-season months. J. Climatol., 4, 297-310.

Williams, P., Jr., 1972: Western Region synoptic analysis-Problems and methods. NOAA/NWS Western Region Tech. Memo. 71: NWSTM WR-71, 71 pp. [Available from NOAA/NWS Western Region Headquarters, 125 S. State Street, Rm. 1311, Salt Lake City, UT 84138-1102.]

Zhang, D., and R. A. Anthes, 1982: A high-resolution model of the planetary boundary layer-Sensitivity tests and comparisons with SESAME-79 data. J. Appl. Meteor., 21, 1594-1609.

Zishka, K. M., and P. J. Smith, 1980: The climatology of cyclones and anticyclones over North America and surrounding ocean environs for January and July, 1950-77. Mon. Wea. Rev., 108, 387-401. 